\title{
Ab Initio Molecular Dynamics Simulations of the Interaction between Organic Phosphates and Goethite
}

\author{
Prasanth B. Ganta ${ }^{1}\left(\mathbb{D}\right.$, Oliver Kühn ${ }^{1,2} \mathbb{D}$ and Ashour A. Ahmed ${ }^{1,2, *(\mathbb{D})}$ \\ 1 Institute of Physics, University of Rostock, Albert-Einstein-Str. 23-24, D-18059 Rostock, Germany; \\ prasanth.ganta@uni-rostock.de (P.B.G.); oliver.kuehn@uni-rostock.de (O.K.) \\ 2 Department of Life, Light, and Matter (LLM), University of Rostock, Albert-Einstein-Str. 25, \\ D-18059 Rostock, Germany \\ * Correspondence: ashour.ahmed@uni-rostock.de; Tel.: +49-381-498-6943
}

Citation: Ganta, P.B.; Kühn, O.; Ahmed, A.A. Ab Initio Molecular Dynamics Simulations of the Interaction between Organic Phosphates and Goethite. Molecules 2021, 26, 160. https://doi.org/ $10.3390 /$ molecules 26010160

Received: 12 November 2020 Accepted: 23 December 2020 Published: 31 December 2020

Publisher's Note: MDPI stays neutral with regard to jurisdictional clai$\mathrm{ms}$ in published maps and institutional affiliations.

Copyright: (C) 2020 by the authors. Licensee MDPI, Basel, Switzerland. This article is an open access article distributed under the terms and conditions of the Creative Commons Attribution (CC BY) license (https:// creativecommons.org/licenses/by/ $4.0 /)$.

\begin{abstract}
Today's fertilizers rely heavily on mining phosphorus $(\mathrm{P})$ rocks. These rocks are known to become exhausted in near future, and therefore effective P use is crucial to avoid food shortage. A substantial amount of $P$ from fertilizers gets adsorbed onto soil minerals to become unavailable to plants. Understanding $\mathrm{P}$ interaction with these minerals would help efforts that improve $\mathrm{P}$ efficiency. To this end, we performed a molecular level analysis of the interaction of common organic P compounds (glycerolphosphate (GP) and inositol hexaphosphate (IHP)) with the abundant soil mineral (goethite) in presence of water. Molecular dynamics simulations are performed for goethiteIHP/GP-water complexes using the multiscale quantum mechanics/molecular mechanics method. Results show that GP forms monodentate (M) and bidentate mononuclear (B) motifs with $\mathbf{B}$ being more stable than $\mathbf{M}$. IHP interacts through multiple phosphate groups with the $3 \mathbf{M}$ motif being most stable. The order of goethite-IHP/GP interaction energies is GP $\mathbf{M}<$ GP $\mathbf{B}<$ IHP $\mathbf{M}<$ IHP $3 \mathbf{M}$. Water is important in these interactions as multiple proton transfers occur and hydrogen bonds are formed between goethite-IHP/GP complexes and water. We also present theoretically calculated infrared spectra which match reasonably well with frequencies reported in literature.
\end{abstract}

Keywords: P-inefficiency; goethite; glycerolphosphate; inositol hexaphosphate; MD simulations; QMMM; binding energies; infrared spectra

\section{Introduction}

Phosphorus (P) scarcity is becoming one of the major global environmental challenges, which needs attention on par with climate change because of the foreseen $\mathrm{P}$ peak scenario [1-3]. The P in today's fertilizer is mostly from mined P rocks, and given the current mining rate they are predicted to be exhausted within next 50-100 years [4,5]. Complicating the situation further, the $\mathrm{P}$ rock reserves are available only in few countries and a $\mathrm{P}$ peak scenario could affect regions like UK, Western Europe, and India who obtain these resources mainly through imports $[2,6,7]$. As $\mathrm{P}$ rock reserves dwindle with time, the food security of P-importing countries is in question, which, in the long-term, might flip oil based economies to P based economies. The oil crisis in the 1970s emphasized the need for renewable energy sources, but unfortunately for the peak $\mathrm{P}$ crisis there is no alternative but to develop ways to increase, reuse, and secure the domestic P production [1,6-8].

The $\mathrm{P}$ input to soil ( $\mathrm{P}$ fertilizers or from nature) is not fully available to plants as most of it is bound to soil organic matter [9-11] or soil minerals [12-16]. To overcome this, fertilizers are often applied in the agriculture industry to maintain and boost the agricultural production. As a side effect, $\mathrm{P}$ bound to minerals runs off along water paths during heavy rains and in the long-term causes eutrophication of waterways [17]. Recent studies show that the soil minerals in rain water retain about $50 \%$ of $\mathrm{P}$ in the soil solution $[18,19]$. In addition, heavy rains further decrease $\mathrm{P}$ efficiency as $\mathrm{P}$-bound soil minerals, i.e., $\mathrm{P}$ colloid complexes, disperse with rain water and accumulate in specific regions unavailable 
to plants [20]. Methods that support effective extraction of $P$ from these colloids would increase domestic $\mathrm{P}$ sources which in turn would improve the food security of global population.

Orthophosphate (OP) is one of the most abundant inorganic phosphate, which exists mainly in the form of phosphate ions $\left(\mathrm{H}_{2} \mathrm{PO}_{4}^{1-}, \mathrm{HPO}_{4}^{2-}, \mathrm{PO}_{4}^{3-}\right)[21,22]$. Regarding organic phosphates, inositol hexaphosphate (IHP) [23-25] and glycerolphosphate (GP) [26-28] are some of the abundant and most common organic phosphates in soil. Often they are present in soil as oxyanions with deprotonated phosphate groups [29-31]. Therefore, the negatively charged phosphates bind to positively charged soil mineral surfaces to form $\mathrm{P}$ colloids. The most common P-fixing minerals are Fe and Al(oxyhydr)oxides [32-34] and $\mathrm{Ca}-$ oxides [33]. Goethite $(\alpha-\mathrm{FeOOH})$ is one of the most reactive and abundant mineral that interacts with phosphates [35]. Strong interactions have been reported for OP [15,36-39] as well as for IHP [30,31,40,41] and GP [29], especially at low to medium $\mathrm{pH}$. The interaction of phosphates with goethite or most minerals is through bonded and non-bonded interactions, for instance, covalent bonds, hydrogen bonds (HBs), van der Waals (vdW) interactions, and electrostatic attraction to form surface complexes [33,42,43]. Numerous studies show that $\mathrm{P}$ compounds with a single phosphate group form one to two covalent bonds between the phosphate group's oxygens and surface iron atoms $[15,36,44]$ within inner-sphere complexes. IHP may bind through one to four of its six phosphate groups $[31,40,41,45]$ to form covalent bonds with surface iron atoms. In contrast, Johnson et al. [30] suggested that IHP forms outer-sphere complexes. In addition to the covalent bonds and electrostatic interaction between phosphates and goethite, water also plays an important role for the stability of these complexes. In fact, the P colloids often exist in a solvated state in both arable and forest soils. The study by Ahmed et al. [46] showed the importance of water in surface complexation reactions and highlighted how water maneuvers the phosphate interaction with mineral by forming strong to moderately strong HBs with phosphates [47,48].

A molecular level study of solvated P colloids could provide additional insight into these interactions and improve our understanding of $P$ availability to plants [13]. Molecular simulations are efficient tools to achieve this with proven track record [42,49]. For instance, Kwon and Kubicki [50] resolved controversies in experimental studies related to phosphate surface complexes on iron hydroxides. They correlated different types of phosphate binding motifs with goethite to $\mathrm{pH}$ and suggested that binding motifs change with $\mathrm{pH}$. Aquino et al. [51] estimated goethite's point of zero charge (PZC) to 9.1 which fits well with experimental values of 6.4-9.7 [22,52,53]. Kubicki et al. [44] explored phosphate and goethite binding motifs and their corresponding stability at different surface planes to find dominant motifs that contribute significantly to infrared (IR) spectra. Ahmed et al. [15] showed that an analysis of theoretical spectra for different motifs could provide an estimate of their ratio of abundance at the goethite surface.

The main objective of the current study is to unravel the interactions of IHP/GP at the 010 goethite-water interface. This is achieved by analyzing binding motifs, interaction energies, and IR spectra obtained using periodic boundary quantum mechanics/molecular mechanics (QM/MM) [54] molecular dynamics simulations.

\section{Modeling and Computations}

\subsection{Goethite Surface}

Goethite is an orthorhombic crystal containing ferric $\left(\mathrm{Fe}^{3+}\right)$ iron which is coordinated by six oxygen atoms [35]. The bulk oxygens are triply coordinated and they are of two distinct types: (1) bridging oxygen coordinated by three iron atoms plus a HB and (2) hydroxyl oxygens coordinated by three iron atoms and one proton, see Figure 1c. Its unit cell contains 16 atoms, i.e., four $\mathrm{FeO}(\mathrm{OH})$ units with lattice constants $a=9.95, b=3.01$, $c=4.62 \AA$. Some common goethite surface planes are 010, 100, 021, and 110 (as per Pnma space group). The IHP and GP interactions with goethite are studied here by considering the 010 goethite surface which is known for its high stability $[55,56]$, see 
Figure 1c. The unsaturated and undercoordinated iron and oxygen atoms at the goethite surface generate an overall positive surface charge that attracts IHP/GP and also water to the surface. Compared to bulk, the surface iron atoms are coordinated by only four oxygens while the bridging and hydroxyl oxygens are coordinated by only two irons instead of three. Modeling an undercoordinated surface supports experimental studies that phosphate (IHP [31] and GP [29]) adsorption occurs mostly at pH lower than the goethite PZC, where its surface is unsaturated and has positive surface charge $[29,31]$.

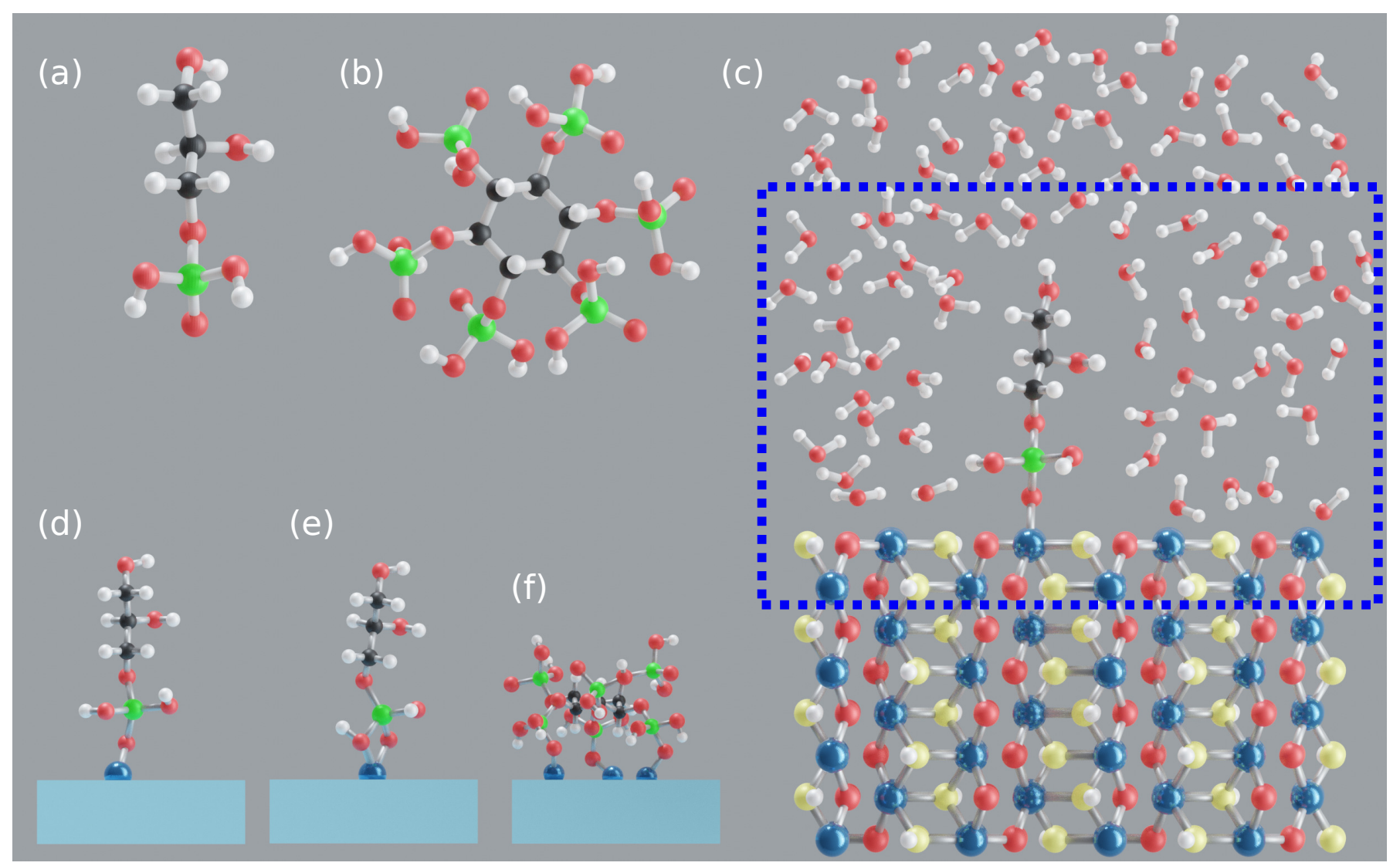

Figure 1. GP $\left[\mathrm{C}_{3} \mathrm{H}_{9} \mathrm{O}_{6} \mathrm{P}\right](\mathbf{a}), \mathrm{IHP}\left[\mathrm{C}_{6} \mathrm{H}_{18} \mathrm{O}_{24} \mathrm{P}_{6}\right](\mathbf{b})$, goethite-GP-water complex (c), $\mathbf{M}$ motif (d), B motif (e), and 3M motif (f). Blue, red, yellow, white, black, and green colors correspond to iron, bridging oxygen, hydroxyl oxygen, hydrogen, carbon, and phosphorus atoms, respectively. The dotted line denotes the QM box.

\subsection{Model Systems}

First, a surface slab is modeled by repetition of the goethite unit cell as $2 a \times 4 b \times 5 c$. Then, GP (see Figure 1a) is added onto the goethite slab to form covalent bond(s) with a surface iron atom, see Figure 1c. The binding motifs considered for goethite-GP complex are based on experimental studies related to OP [22,57] and organic compounds with monophosphate groups [29,43] interacting with goethite. The study by Li et al. [29] of GP adsorption on goethite suggests that GP predominantly forms monodentate mononuclear motifs $(\mathbf{M}, 1 \mathrm{Fe}+1 \mathrm{O}$ a covalent bond between $\mathrm{Fe}$ atom and phosphate free oxygen, see Figure 1d). However, considering OP's [58] interaction with goethite, an additional motif called bidentate mononuclear motif $(\mathbf{B}, 1 \mathrm{Fe}+2 \mathrm{O}$ two covalent bonds between Fe atom and unprotonated and protonated phosphate $\mathrm{O}$ atoms, see Figure $1 \mathrm{e}$ ) is modeled. The bidentate binuclear motif (BB, $2 \mathrm{Fe}+2 \mathrm{O}$, two covalent bonds between two surface Fe atoms and two oxygens from phosphate, see Figure S4a) which is commonly discussed for OP interaction with goethite $[22,36,50]$ is not considered here as the distance between consecutive Fe atoms does not match the range of distances between oxygen atoms in the phosphate group. 
Similarly, IHP (see Figure 1b) is added onto the goethite surface to form goethite-IHP complexes. The IHP interaction with goethite is different compared to GP because of the additional phosphate groups. Guan et al. [45] studied IHP adsorption onto aluminum hydroxide and showed that IHP binds to the surface through two phosphate groups. Moreover, Celi et al. [31] and Ognalaga et al. [40] suggested that IHP interacts with goethite through multiple phosphate groups. Unlike for OP and GP, there is no suggestion for a clear dominant motif for IHP interaction with goethite. Therefore, in addition to the $\mathbf{M}$ and $\mathbf{B}$ motifs, a tridentate motif $\mathbf{3} \mathbf{M}(\mathbf{3} \mathbf{M}, 3 \mathrm{Fe}+3 \mathrm{O}$ three covalent bonds between three surface $\mathrm{Fe}$ atoms and one protonated, two unprotonated phosphate $\mathrm{O}$ atoms, see Figure $1 \mathrm{f}$ ) is considered. The $\mathbf{3 M}$ motif is considered here based on the goethite surface Fe atom's and IHP O atom's structural flexibility to form bonds.

The complexes discussed so far are solvated to include the effects of water on their interactions. The goethite-IHP/GP complexes are solvated perpendicular to the studied surface plane up to $\approx 18 \AA$ using VMD [59] at a density of $\approx 1 \mathrm{~g} \mathrm{~cm}^{-3}$, see Figure 1c. To ease the discussion about the interactions, the Fe/Al-bonded oxygens are denoted as $\mathrm{O}_{\mathrm{p}}$. Note that even though the initial motifs considered here may not include all possible surface configurations they should allow us to draw conclusions from common motifs.

\subsection{Computational Details}

The atoms in the modeled complexes are separated into two regions as required by the QM/MM method [54,60]. The atoms of the reactive region (QM) of goethite-IHP/GPwater complexes include the top goethite layer, phosphate, and water within $\approx 10 \AA$ from goethite surface. The average number of QM atoms in each model is around 350-400 depending on the complex; the total average number of atoms per each model is around 1200-1250. The atoms excluded from the QM region are described at the MM level with classical force fields (FF). Note that simulating the above complexes with 1200+ atoms using pure QM methods is a computational roadblock [42,61], and to overcome this the $\mathrm{QM} / \mathrm{MM}$ approach is adopted here.

The potential and forces of the QM subsystems are calculated using density functional theory (DFT) as implemented in the Quickstep code [62]. Here, the nucleus and highly localized core electrons of atoms are replaced by Goedecker-Teter-Hutter (GTH) pseudopotentials [63], while the valance electrons are described with the double- $\zeta$ valance-polarized MOLOPT (DZVP-MOLOPT-SR-GTH) basis set [64]. For water atoms, the valance electrons are defined with the simpler single- $\zeta$ valance (SZV-MOLOPT-SR-GTH) basis set to further reduce computational cost. The exchange correlation interactions and vdW interactions are included with Perdew-Burke-Ernzerhof (PBE) [65] exchange correlation functional and D3 empirical dispersion correction [66], respectively. The MM part is simulated with the FIST module [67], which is an integral part of CP2K [68,69]. The goethite surface is modeled with the CLAYFF FF [70] and the water with the single point charge (SPC) water model [71]. For phosphates IHP and GP, CHARMM FF are obtained from SwissParm, a FF generation tool [72]. Both CLAYFF and CHARMM FFs are compatible with the SPC water model.

The interaction between $\mathrm{QM}$ and MM subsections is simulated by Gaussian expansion of the electrostatic potential method (GEEP) [73] which is part of CP2K. This method defines MM charges as smeared out Gaussians and adopts efficient screening techniques to reduce the computational cost in calculating mutual interaction energies between QM and MM subsystems. There is a variety of $\mathrm{QM} / \mathrm{MM}$ methods available that differ based on the level of theory used to define QM and MM mutual interactions. Here, the electrostatic embedding type of QM/MM method is employed which allows $\mathrm{MM}$ atoms to polarize $\mathrm{QM}$ atoms and thus to include the effect of surrounding atoms onto the reactive region [60]. For all complexes, the QM box size is $2 a \times 22 \times 5$ c, i.e., $19.9 \times 22 \times 23.1 \AA$, see Figure 1 c, and the remaining region is $\mathrm{MM}$.

Molecular Dynamics (MD) simulations are employed to sample the equilibrium dynamics including reactive events. As the phosphate interaction at goethite-water interface 
involve proton transfer events and covalent bond changes [46-48], using the QM/MM MD technique is mandatory. Specifically, the electron density cut-off for the auxiliary plane wave basis set is chosen to be 500 Ry with SCF convergence threshold of $10^{-4}$ Hartree. The MD simulations are performed for 25 ps with a $0.5 \mathrm{fs}$ time step and the temperature is maintained at $300 \mathrm{~K}$ with canonical sampling through the velocity rescaling thermostat (CSVR) [74].

Each model has been equilibrated for about 10 ps. Interaction energies and information about geometries have been obtained from a subsequent 15 ps production trajectory. Specifically, the interaction energy between the goethite surface and IHP is calculated for every 100 fs (i.e., 150 snapshots) along the production trajectory by using

$$
\mathrm{E}_{\text {int }}=\mathrm{E}_{\text {goe-IHP}- \text { complex }}-\left(\mathrm{E}_{\text {goe }}+\mathrm{E}_{\mathrm{IHP}}\right) \text {. }
$$

The terms $\mathrm{E}_{\text {goe-IHP-complex, }} \mathrm{E}_{\mathrm{IHP}}$, and $\mathrm{E}_{\text {goe }}$ denote total electronic energy of the goethite-IHP-complex, IHP, and goethite surface, respectively. The basis set superposition error (BSSE) in interaction energies is corrected using the counterpoise scheme [75]. The interaction energies that involve water are divided by the total number of water molecules in the simulation box to obtain per water molecule interaction energies for better comparison.

Infrared (IR) spectra for IHP and GP adsorbed onto goethite are calculated using the TRAVIS [76] software. In TRAVIS the IR spectra are obtained by Voronoi tessellation of the electron density yielding molecular dipole moments from bulk phase MD simulations $[77,78]$. This was done along a 30 ps equilibrium trajectory. The electron density is calculated for each $4 \mathrm{fs}$, i.e, every 8th snapshot of production trajectory and the massive $(\approx 2$ TB) electron density files are compressed using the bqb compression tool [79] compatible with TRAVIS. The compressed bqb files are then provided to TRAVIS software to calculate IR spectra. Here, the IR spectra are calculated for the frequency range of 950 to $1250 \mathrm{~cm}^{-1}$, where the characteristic peaks related to phosphate stretching modes are observed.

\section{Results and Discussion}

\subsection{Goethite-GP-Water Interactions}

\subsubsection{GP M Motif}

A stable $\mathbf{M}$ motif is observed throughout the production trajectory with an average $\mathrm{Fe}-\mathrm{O}_{\mathrm{p}}$ bond length of $2.0 \AA$ and average Fe-P distance of $3.2 \AA$, see Figure $2 \mathrm{~b}$. During early stages of equilibration, GP has formed an average of seven HBs with water, of which one is strong enough for a proton transfer to happen from GP to water, see Figure $3 a$. By the end of the equilibration, GP is twice deprotonated with one proton transfer to water and another to surface, see Figure $3 a-b$. A proton transfer is observed from GP to water (see Figure 3c) in the production trajectory; therefore, GP is three times deprotonated and its phosphate group completely deprotonated. In Figure $3 b$, a proton transfer event is observed from goethite surface oxygen to water. On average $8 \mathrm{HBs}$ are observed between GP and water over the course of the production trajectory, see Figure S4b. The HBs are calculated using the VMD [59] plugin with HB donor-acceptor distance selected as $3 \AA$. Figure $3 \mathrm{~d}$ shows a stable GP $\mathbf{M}$ motif at 25 ps. 


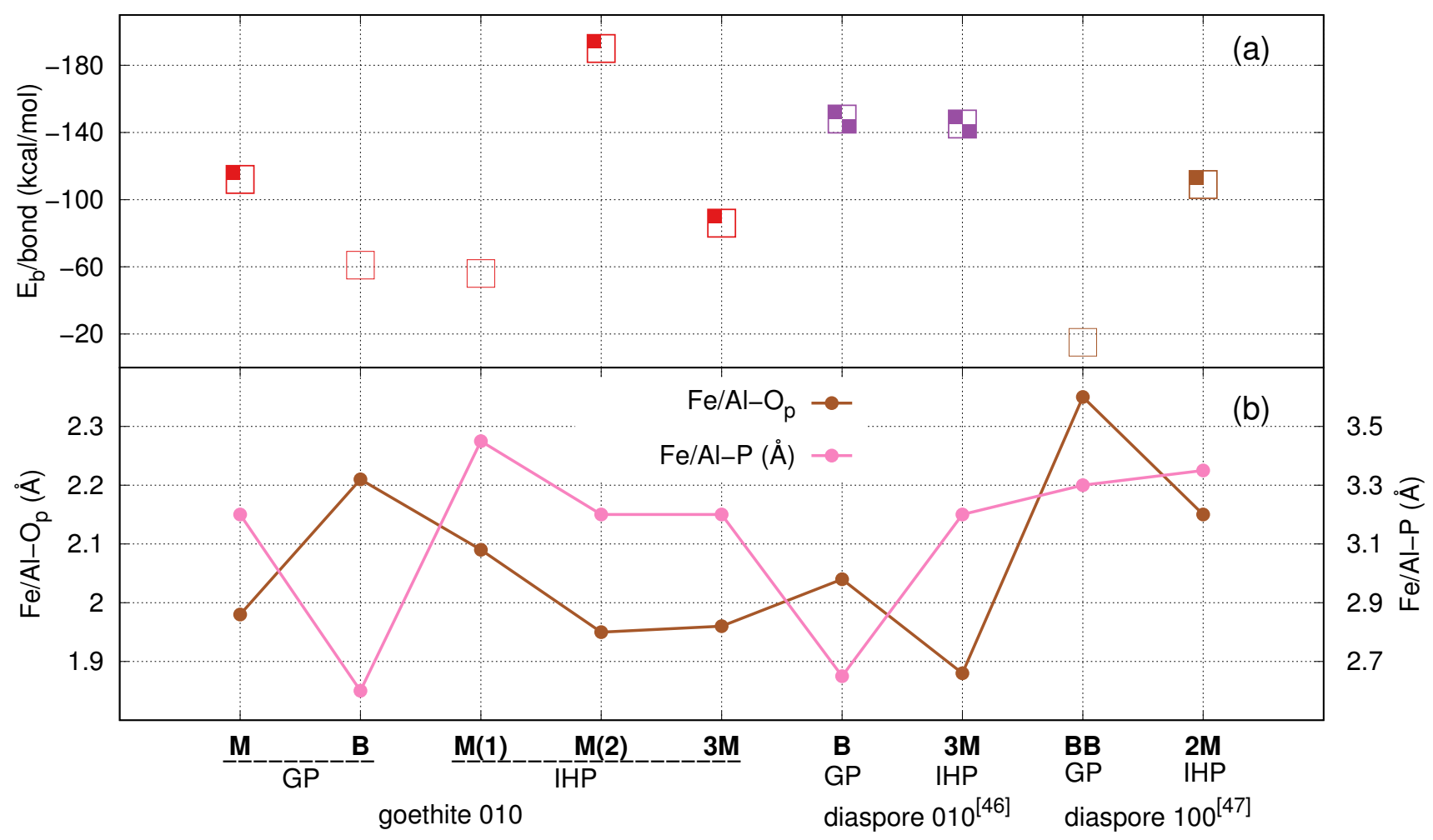

Figure 2. Comparison plot of interaction energies per bond $\mathrm{E}_{\mathbf{b}}(\mathbf{a})$ and $\mathrm{Fe}-\mathrm{O}_{\mathrm{p}}, \mathrm{Fe}-\mathrm{P}$ distances $(\mathbf{b})$. Panels $(\mathbf{a}, \mathbf{b})$ also contain data for diaspore-IHP/GP-water complexes [47,48]. In the top figure, the number of filled subsquares denote the total number of proton transfers from IHP/GP to surface and center of box denotes the binding energy. The square with zero filled subsquares denotes zero proton transfers from phosphate to the surface.

The average interaction energy between goethite and GP calculated using Equation (1) is $-112 \mathrm{kcal} / \mathrm{mol}$, see Figure 2a. The average GP-water interaction energy per water molecule is $-2.3 \mathrm{kcal} / \mathrm{mol}$. The accumulation of water around the goethite surface suggests that water experiences a strong electrostatic pull from goethite surface, see Figure S5. The average goethite-water interaction energy is $-6.8 \mathrm{kcal} / \mathrm{mol}$, which is larger than the GP-water interaction energy. The stronger goethite-water interaction is due to multiple $\mathrm{Fe}-\mathrm{O}_{\mathrm{H}_{2} \mathrm{O}}$ covalent bonds (see Figure S4c), proton transfers, and HBs between goethite active sites and water.

\subsubsection{GP B Motif}

The initial $\mathbf{B}$ motif was found stable during the production trajectory with a mean average $\mathrm{Fe}-\mathrm{O}_{\mathrm{p}}$ bond length of $2.21 \AA$ and $\mathrm{Fe}-\mathrm{P}$ distance of $2.6 \AA$. The mean average $\mathrm{Fe}-\mathrm{O}_{\mathrm{p}}$ bond length observed here is longer than in the $\mathbf{M}$ motif case, probably due to the repulsion between the bonded oxygens, see Figure $2 \mathrm{~b}$. In contrast to the $\mathbf{M}$ motif, proton transfer events are not observed from GP to the goethite surface. GP formed an average of eight HBs with water during equilibration stage and of these two yielded proton transfers from GP to water, see Figure 3e-f. Therefore, GP is deprotonated twice at the end of equilibration and during the production trajectory it formed an average of eight HBs with water. The snapshots in Figure $3 \mathrm{~g}$ and $\mathrm{h}$ show the GP B motif at 20 and $25 \mathrm{ps}$, respectively.

The goethite-GP per bond interaction energy here is $-61 \mathrm{kcal} / \mathrm{mol}$ per bond which is less than for the GP M motif because of the additional proton transfer observed in the latter case. However, the total interaction energy $(-122 \mathrm{kcal} / \mathrm{mol})$ here is higher than for the GP M motif, see Figure 2a. The GP-water interaction energy is $-1.9 \mathrm{kcal} / \mathrm{mol}$, which is smaller than for $\mathbf{M}$ motif case, probably due to the additional proton transfer from GP to water in the $\mathbf{M}$ motif. 

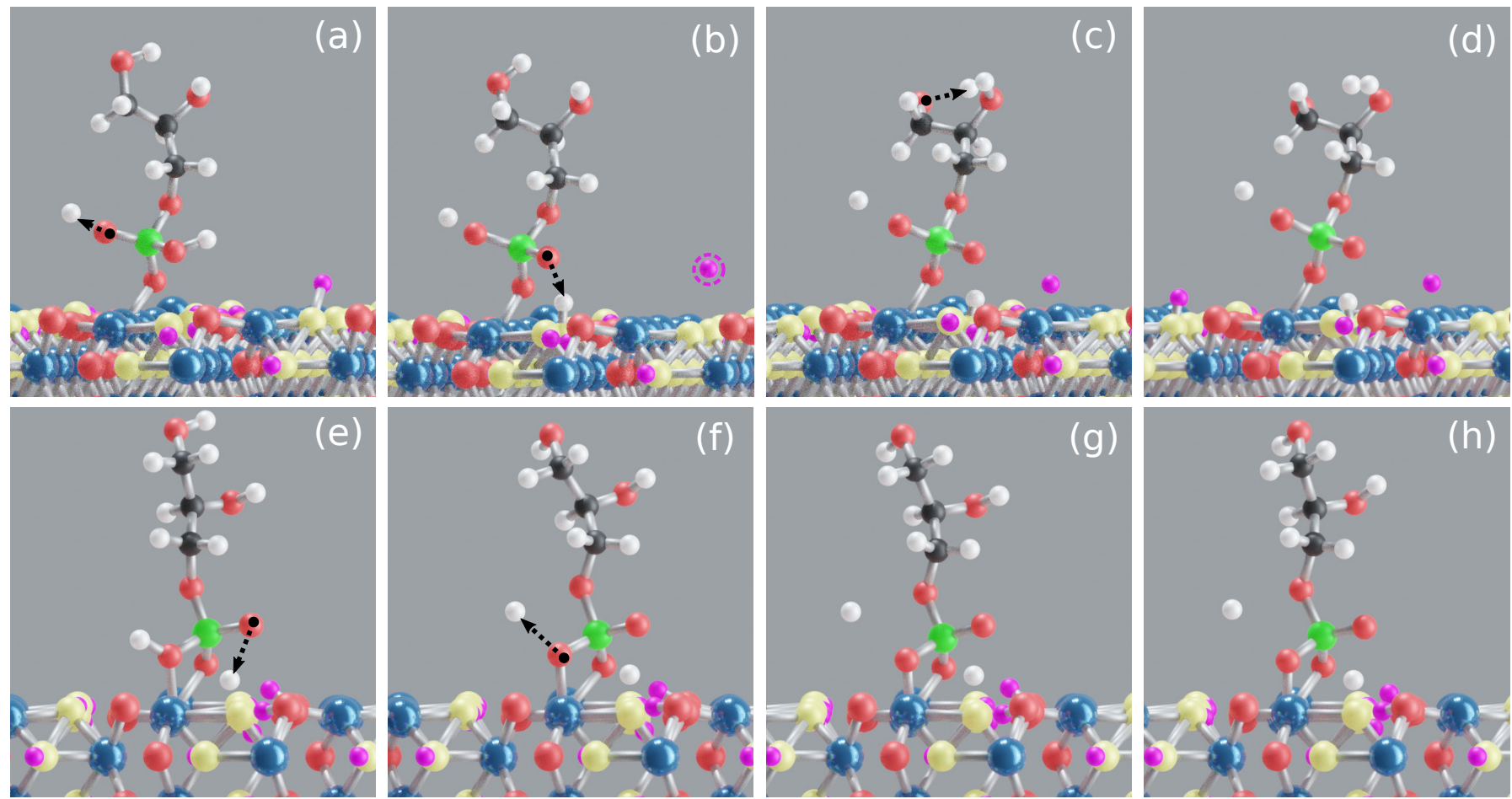

Figure 3. Snapshots of goethite-GP-water models along the simulation trajectory. Proton transfer from GP to water (a), a proton transfer from GP to surface and from surface to water (b), a proton transfer from GP to water (c), a stable M motif at 25 ps (d), proton transfers from GP to water $(\mathbf{e}, \mathbf{f})$, and $\mathbf{B}$ motif at $20 \mathrm{ps}(\mathbf{g})$ and 25 ps (h). As proton transfer events are common in these interactions, the goethite surface hydrogen atoms and GP's hydrogen atoms are shown in violet and white colors to avoid confusion. Moreover, the surrounding water is ignored here for better visualization. Snapshots $(\mathbf{a}, \mathbf{b}, \mathbf{e}, \mathbf{f})$ are from equilibration phase.

\subsubsection{Discussion of Goethite-GP-Water Interactions}

The study by Li et al. [29] of GP on goethite suggested the formation of only the $\mathbf{M}$ motif and considered that the $\mathbf{B}$ motif could not be formed due to steric hindrance of the organic moiety in the GP molecule. In addition, Persson et al. [43] suggested a dominant $\mathbf{M}$ motif for monomethyl phosphate (MMP; $\mathrm{CH}_{3}-\mathrm{H}_{2} \mathrm{PO}_{4}$ ) adsorption onto goethite. However, similar to our previous studies [47,48], we find that GP forms stable and strong B or BB motifs, see Figure 2a. In addition, Lü et al. [80] suggested that molecules with similar binding mechanism like GP such as glucose 6-phosphate and adenosine mono/triphosphates form nonprotonated bidentate complexes within first ten minutes after mixing. Furthermore, OP is known to form $\mathbf{M}, \mathbf{B}$, and $\mathbf{B B}$ motifs when interacting with goethite $[33,44,50,58]$. This raises the question of why the $\mathbf{M}$ motif could be the dominant species for GP on goethite, despite the fact that the binding energy for the $\mathbf{B}$ motif is stronger, see Figure 2a. Note that the interaction energies presented in Figure 2a are per bond. For IHP, we found a transformation of $\mathbf{B}$ motif to $\mathbf{M}$ motif on diaspore surface $[47,48]$ because of intermolecular HBs in IHP and its strong interaction with water. Based on this, and on the study by Li et al. [29], one might assume that GP's HBs with water or its steric hinderance might hinder the $\mathbf{B}$ motif. Nevertheless, Abdala et al. [58] showed that at low $\left(1.25 \mu \mathrm{molm}^{-2}\right)$, medium $\left(2.5 \mu \mathrm{molm}^{-2}\right)$, and high $\left(10 \mu \mathrm{molm}^{-2}\right)$ surface loading of OP onto goethite, the observed motifs are at low $\mathbf{B}(48 \%), \mathbf{B B}(47 \%)$, and $\mathbf{M}(\approx 0)$; at medium B $(77 \%)$, BB $(25 \%)$, and $\mathbf{M}(\approx 0)$; and at high $\mathbf{B}(\approx 0), \mathbf{B B}(18 \%)$, and $\mathbf{M}(77 \%)$. This clearly shows that for low surface loading the $\mathbf{B}$ and $\mathbf{B B}$ motifs are dominant motifs whereas for high surface loading the $\mathbf{B}$ motif is not formed in the first place. In addition to surface loading, the surface type is also vital in deciding the dominant motifs of phosphates on surface $[15,44]$. For the 010 goethite surface, the theoretical study of single phosphate molecule interaction at goethite-water interface by Ahmed et al. $[15,46]$ showed that the 
B motif has a stronger binding than M. Further, the protonation state of GP's phosphate group here could be understood from the study of Sheals et al. [81] of glyphosate (GLP, $\left.\mathrm{H}_{2} \mathrm{PO}_{3}-\mathrm{CH}_{2}-\mathrm{NH}_{2}-\mathrm{CH}_{2}-\mathrm{COO}\right)$ on goethite; the twice deprotonated phosphate species dominate at the low surface adsorption densities and the monoprotonated phosphate species dominate at high surface adsorption densities. Correlating the current study with the above literature, the GP binds through a $\mathbf{B}$ motif with a twice deprotonated phosphate group dominantly at low surface adsorption density. At high surface adsorption density, GP binds preferentially through a $\mathbf{M}$ motif with a monoprotonated phosphate group.

The Fe-P distance observed here for the GP $\mathbf{M}$ motif is within the range of $\mathrm{Fe}-\mathrm{P}$ distances observed in literature for goethite-phosphate complexes: 3.13-3.37 [82], 3.17-3.32 [83], 3.38 [44], 3.20 [46], and 3.41 [15], see Figure 2b. For the B motif, even though the calculated phosphate bond in this motif exhibits a strong interaction energy [46-48], it is not often discussed in experimental studies [22,44]. X-ray absorption studies of Abdala et al. [58] showed that the Fe-P distance observed for $\mathbf{B}$ motif case is around $2.85 \AA$, which is close to the value observed here, see Figure $2 \mathrm{~b}$. Furthermore, similar Fe-P values are observed for $\mathbf{B}$ motif in theoretical studies, i.e., 2.64 [46] and $2.58 \AA$ [15]. Comparing the present interaction energies with other systems we notice the following. The present $\mathbf{B}$ motif exhibits stronger binding energy than the M motif, similar to the OP [46] and GLP [15] interaction with 010 goethite surface. Moreover, OP and GLP bind more strongly with goethite than with water, as observed for GP and water here. This suggests that phosphates often have the ability to replace water from goethite surface.

\subsection{Goethite-IHP-Water Interaction}

\subsubsection{IHP M Motifs}

Here, the initial $\mathbf{M}\left(\mathrm{Fe}-\mathrm{O}_{\mathrm{p}}\right)$ and $\mathbf{B}\left(\mathrm{O}_{\mathrm{p}}-\mathrm{Fe}-\mathrm{O}_{\mathrm{p}}\right)$ motifs (see Figure S3a,b) resulted in two different $\mathbf{M}$ motifs. $\mathbf{M ( 1 )}$ corresponds to the initial $\mathbf{M}$ configuration, with an average $\mathrm{Fe}-\mathrm{O}_{\mathrm{p}}$ bond length and $\mathrm{Fe}-\mathrm{P}$ distance of 2.09 and $3.45 \AA$, respectively, see Figure $2 \mathrm{~b}$. Two proton transfer events are observed from IHP to water in the equilibration stage, see Figure 4a,b. Moreover, a proton transfer is observed from goethite to water, see Figure 4a. During the production trajectory, IHP is twice deprotonated and the protonation state of IHP has not altered. It has formed an average of $22 \mathrm{HBs}$ with water. In addition, intramolecular HBs are observed between adjacent phosphate groups along the whole MD trajectory, see Figure $4 \mathrm{~b}-\mathrm{d}$. Similar to our previous studies [47,48], the HBs formed between IHP and water and the intramolecular HBs in IHP are mostly strong to moderately strong HBs. Figure $4 \mathrm{~d}$ shows the M(1) motif at $25 \mathrm{ps}$. The average goethite-IHP and IHP-water interaction energies observed here are -56 and $-5.5 \mathrm{kcal} / \mathrm{mol}$, respectively. The goethite-water interaction energy here is $-5.7 \mathrm{kcal} / \mathrm{mol}$ which is less than in the GP's M motif.

In M(2) motif case, the initial configuration was the $\mathbf{B}$ motif (see Figure S3b), which transformed to form $\mathrm{M}(2)$. Here, one of the $\mathrm{Fe}-\mathrm{O}_{\mathrm{p}}$ bonds is dissociated, and for the other bond the average $\mathrm{Fe}-\mathrm{O}_{\mathrm{p}}$ bond length and $\mathrm{Fe}-\mathrm{P}$ distance is found to be 1.95 and $3.2 \AA$, respectively, see Figure $2 \mathrm{~b}$. In the equilibration phase, a proton transfer event is observed from IHP's oxygen to the surface (see Figure 4a), followed by formation of an intramolecular $\mathrm{HB}$ between the same oxygen and an adjacent phosphate group, see Figure $4 \mathrm{~b}$. IHP has formed around $20 \mathrm{HBs}$ with water and two of them are apparently strong enough such that proton transfer events are observed from IHP to water. In addition, IHP has formed multiple intramolecular HBs between phosphate groups, see Figure $4 \mathrm{f}-\mathrm{h}$. During the production trajectory, IHP is three times deprotonated with one proton transfer to surface and two to water. One of the protons transferred from IHP to water formed an HB with the goethite surface, see Figure $4 \mathrm{~g}-\mathrm{h}$. The time averaged goethite-IHP interaction energy observed here is $-190 \mathrm{kcal} / \mathrm{mol}$ which is higher than the $\mathbf{M ( 1 )}$ motif case due to additional proton transfers from IHP to goethite surface observed here, see Figure 2e-h. 


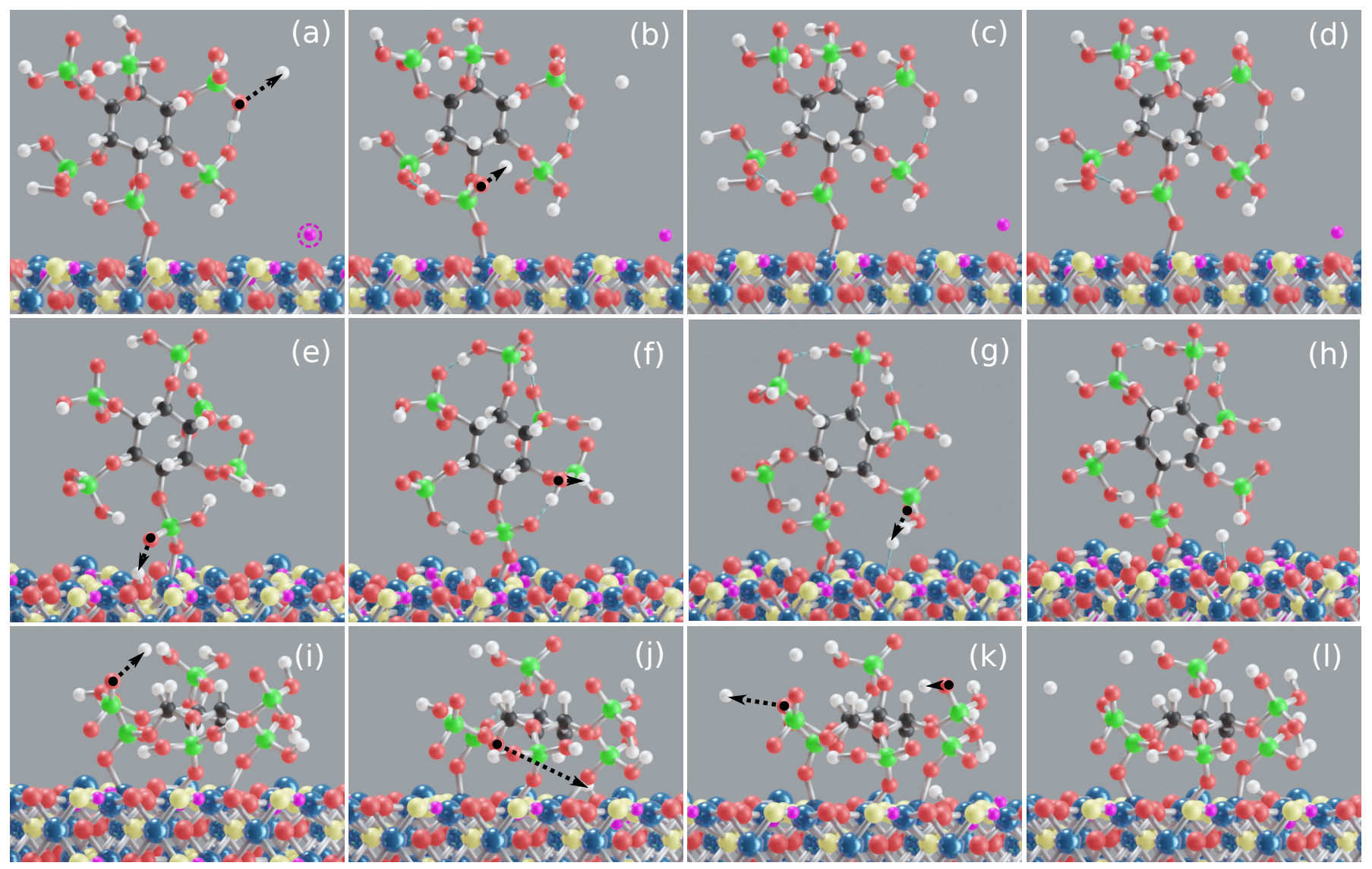

Figure 4. Snapshots of goethite-IHP-water models along the simulation trajectory. In M(1) motif, proton transfer from IHP to water and from goethite surface oxygen to water (a), intramolecular HB and a proton transfer from IHP to water (b), and M(1) motif at 17 and 25 ps (c,d). In M(2) motif, proton transfer from IHP to surface (e), protons transfer from IHP to water (f,g), and $\mathbf{M}(\mathbf{2})$ motif at $25 \mathrm{ps}(\mathbf{h})$. In $3 \mathbf{M}$ motif, three proton transfers from IHP to water (i,k) and a proton transfer from IHP to surface (j), 3M motif at 25 ps (1). As proton transfer events are common in these interactions, the goethite surface hydrogen atoms and IHP's hydrogen atoms are shown in violet and white colors to avoid confusion. Moreover, the surrounding water is ignored here for better visualization. Snapshots that show proton transfers are from the equilibration phase.

\subsubsection{IHP 3M Motif}

Here, IHP is aligned parallel to the surface to form three $\mathrm{Fe}-\mathrm{O}_{\mathrm{p}}$ covalent bonds as shown in Figure 1c. A stable 3M motif is observed during the production trajectory with mean average $\mathrm{Fe}-\mathrm{O}_{\mathrm{p}}$ bond length of $1.96 \AA$ and the corresponding mean average Fe-P distance of $3.2 \AA$, see Figure $2 b$, respectively. During equilibration, IHP has formed an average of $22 \mathrm{HBs}$ with water of which three transformed to proton transfers from IHP to water, see Figure $4 \mathrm{i}, \mathrm{k}$. Furthermore, one proton transfer is observed from IHP to the surface, see Figure 4j. The equilibrated IHP is four times deprotonated with three proton transfers to water and one to the surface. The average number of HBs formed between IHP and water in production trajectory is around 23. The Figure 41 shows the IHP $\mathbf{3 M}$ motif at 25 ps.

The time averaged goethite-IHP interaction energy per bond observed here is $-86 \mathrm{kcal} / \mathrm{mol}$. The goethite-IHP per bond interaction energy here is small compared to the $\mathbf{M ( 2 )}$ motif case, but the overall interaction energy is higher than for both $\mathbf{M}$ motif cases, see Figure 2a. The IHP-water interaction energy is $-7.8 \mathrm{kcal} / \mathrm{mol}$ which is higher than for the IHP $\mathbf{M}$ motif cases because of an additional proton transfer from IHP to water. 


\subsubsection{Discussion of Goethite-IHP-Water Interactions}

Evaluating the interaction of the IHP phosphate groups with goethite, the $\mathbf{B}$ motif is found to be unstable here, similar to our previous studies $[47,48]$ for IHP interaction with diaspore. To our knowledge, studies in literature have not mentioned the existence of $\mathbf{B}$ or $\mathbf{B B}$ motifs for IHP interacting with minerals. However, the $\mathbf{M}$ motif is often observed in theoretical studies $[45,47,48]$ for IHP. Interestingly, for the number of phosphate groups which will bind to the surface different suggestions exist, ranging from four [40], three [45,47], two [47,48], one [47,48], and 0 [30]. The present $\mathbf{M}$ and $\mathbf{3} \mathbf{M}$ stable motifs add to the list. The goethite-water interaction energy observed here is less than in the GP case. The weaker interaction of water in the latter case is in line with the study by Celi et al. [31] who showed that IHP adsorption on goethite makes the surface more negative than in case of OP.

Numerous studies show that IHP has the ability to compete with OP for the same binding sites and it could release and replace OP on goethite [23]. Comparing IHP and GP interaction energies, IHP exhibits stronger adsorption onto goethite than GP (see Figure 2a) which is in line with experiment [84] and our previous studies $[47,48]$ for diaspore. Therefore, IHP has the ability to replace GP and the order of adsorption energies is IHP > GP $>$ water. The Fe-P distances observed here are in close match to the values observed in experimental $[58,82]$ and theoretical studies $[15,44,46,83]$ of OP adsorption onto goethite. This is in line with Celi et al. [85] suggestion that IHP phosphate groups react with goethite in the same way as OP. Compared to GP, one could also infer that the changes in the phosphate group's geometry observed upon binding to goethite is similar for IHP and GP.

\subsection{Theoretical IR Spectra of GP and IHP Adsorbed onto Goethite}

The IR spectra of IHP/GP adsorbed onto goethite are calculated only for the stable motifs observed above, i.e, $\mathbf{M}$ and $\mathbf{B}$ of GP and $\mathbf{M}$ and $\mathbf{3} \mathbf{M}$ of IHP. These motifs remained stable also during the extended trajectory used to calculate spectra, see Figures S6 and S7. The theoretical spectra calculated for these motifs are normalized and illustrated in Figure 5. The spectral analysis here is confined to $950-1250 \mathrm{~cm}^{-1}$ mainly to focus on the [P-O] stretching modes which are dominant in this range [22,86,87]. Therefore, the discussion below is mainly focused on phosphate ion bondings observed in the production trajectory and the corresponding IR spectra from literature. However, the peak positions of the IR spectra are known to shift differently with environmental factors such as water content and $\mathrm{pH}$ [50]. Especially nonprotonated oxygens of phosphate group are more sensitive to water hydrogens and hydroxyl groups and form HBs which might influence the spectra $[50,88,89]$. Both IHP and GP form strong to moderately strong HBs with surrounding water $[47,48]$ and also contain nonprotonated oxygens, see Figures 3 and 4 . Therefore, the calculated spectra here should reflect these interactions. The charge superscript is ignored when representing the phosphate ion bondings, e.g., $\mathrm{FeH}_{2} \mathrm{PO}_{4}$ or $\mathrm{FeHPO}_{4}$, as these complexes are part of GP or IHP but not a molecule on their own.

Arai and Sparks [90] predicted the type of aqueous phosphate species based on the number of bands in IR spectra and the corresponding symmetry. According to their study, the aqueous phosphate species and their corresponding symmetry with number of bands (in parentheses) are $\mathrm{PO}_{4}-\mathrm{T}_{\mathrm{d}}(1), \mathrm{HPO}_{4}-\mathrm{C}_{3 \mathrm{v}}(3), \mathrm{H}_{2} \mathrm{PO}_{4}-\mathrm{C}_{2 \mathrm{v}}(4)$, and $\mathrm{H}_{3} \mathrm{PO}_{4}-\mathrm{C}_{3 \mathrm{v}}(3)$. The study also showed that after $\mathrm{OP}$ binds to goethite the symmetry is reduced and the aqueous phosphate IR bands further split to form additional bands. Here, the symmetry of the phosphate group/s of IHP and GP is further reduced compared to OP bonded to goethite because of the $\mathrm{P}-\mathrm{O}-\mathrm{C}$ connection. Therefore, in the current study the spectrum assignment is performed based on the phosphate group moiety and its binding motif with goethite rather than symmetry.

Before we start the analysis some limitations about this approach should be mentioned. In an experimental set-up the IR spectra are obtained for an ensemble of molecules interacting with different goethite surface types. In contrast, here the analysis is performed for a single IHP/GP molecule interacting with only one goethite surface type. Furthermore, 
the IR bands and their corresponding assignments may vary based on $\mathrm{pH}$, experimental conditions, and surface crystallinity [44]. Ahmed et al. [15] provided a novel approach to this problem by calculating weighted averages of theoretical IR spectra involving simultaneously the most common and abundant motifs and surface planes. This study also emphasized the idea that an abundant motif's characteristics dominate the overall spectra which is in line with experimental studies [22,57].

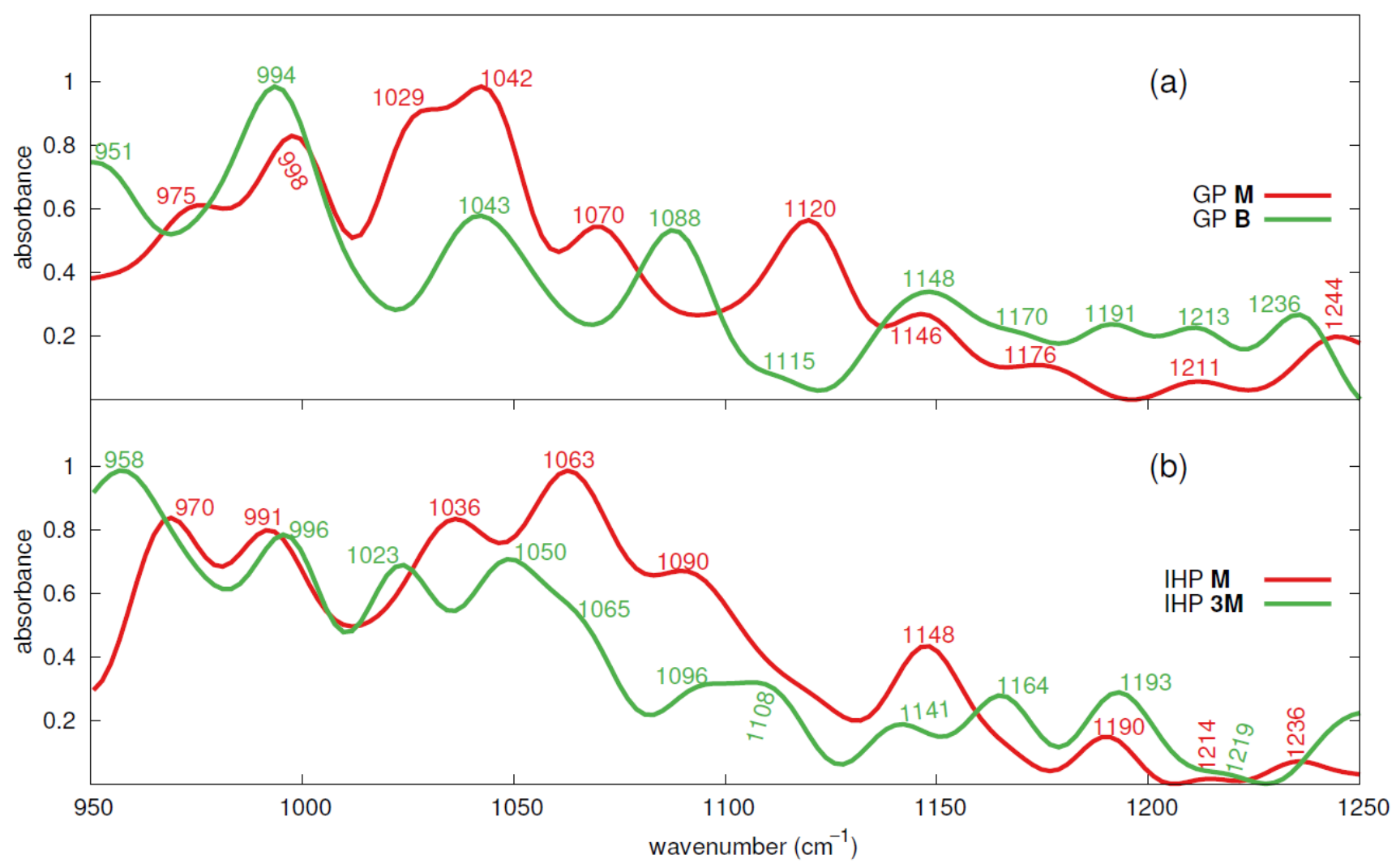

Figure 5. Calculated IR spectra of GP $\mathbf{M}$ and $\mathbf{B}$ motifs (a) and IHP $\mathbf{M}$ and $3 \mathbf{M}$ motifs (b).

\subsubsection{GP IR Spectra}

In the GP M motif case, a deprotonated phosphate species is observed throughout the production trajectory. Therefore, the phosphate species observed here is $\mathrm{FePO}_{4}$. The IR spectrum for GP exhibits ten bands at 975, 998, 1029, 1042, 1070, 1120, 1146, 1176, 1211, and $1244 \mathrm{~cm}^{-1}$ in the frequency range $950-1250 \mathrm{~cm}^{-1}$, see Figure $5 \mathrm{a}$. The first six peaks are of high to moderately high intense, whereas the remaining ones are less intense. The peaks at 1176 and $1211 \mathrm{~cm}^{-1}$ are less intense and wide ranged peaks distributed in frequency range of 1165 to $1187 \mathrm{~cm}^{-1}$ and 1200 to $1224 \mathrm{~cm}^{-1}$. In the GP B motif case also a deprotonated phosphate species is also observed throughout the simulation trajectory. Here, the GP exhibits ten bands at 951, 994, 1043, 1088, 1115, 1148, 1170, 1191, 1213, and $1236 \mathrm{~cm}^{-1}$. Here, only the first four bands are of high to moderately high intense and the remaining ones are less intense, see Figure $5 \mathrm{a}$. The bands at $1115 \mathrm{~cm}^{-1}$ and $1170 \mathrm{~cm}^{-1}$ are shoulder bands distributed in the range of 1109 to $1119 \mathrm{~cm}^{-1}$ and 1164 to $1175 \mathrm{~cm}^{-1}$, respectively. The GP $\mathbf{M}$ and $\mathbf{B}$ motif cases have matching bands within $\pm 6 \mathrm{~cm}^{-1}$ of frequencies at 996, 1041, $1117,1147,1173,1212$, and $1240 \mathrm{~cm}^{-1}$. In the following we compare these findings with previous studies.

GP M motif case: Lincoln and Stranks [91] studied phosphate binding to Co in the $\mathrm{Co}\left(\mathrm{NH}_{3}\right)_{5} \mathrm{PO}_{4}$ complex and assigned bands at 980 and $1030 \mathrm{~cm}^{-1}$ to [P-OCo] and [P-O] modes of monodentate deprotonated phosphate group $\left(\mathrm{CoPO}_{4}\right)$, respectively. Tribe et al. [83] assigned bands at 979 and $1032 \mathrm{~cm}^{-1}$ to [P-O] modes of $\mathrm{FePO}_{4}$ phosphate 
species for glyphosate adsorption onto goethite. Therefore, the bands at 975 and $1029 \mathrm{~cm}^{-1}$ here are assigned to [P-OFe] and [P-O] modes. Compared to the study by Li et al. [29] of GP adsorption onto goethite, the bands at 998, 1042, 1120, and $1146 \mathrm{~cm}^{-1}$ could be assigned to [P-O] stretching mode, see Table 1 and Figure 5 . The band at $998 \mathrm{~cm}^{-1}$ could also be assigned to $[\mathrm{P}-\mathrm{OFe}]$ stretching mode as multiple studies $[15,22,57,83]$ assigned bands around this frequency to the same stretching mode. Tribe et al. [83] assigned a band at $1063 \mathrm{~cm}^{-1}$ to $[\mathrm{P}-\mathrm{O}]$ stretching mode for the $\mathrm{FeHPO}_{4}$ complex, and therefore the band at $1070 \mathrm{~cm}^{-1}$ here could be assigned to a $[\mathrm{P}-\mathrm{O}]$ stretching mode. The less intense band at $1176 \mathrm{~cm}^{-1}$ might correspond to [P-O] asymmetric stretching mode as Li et al. [29] assigned a band at $1180 \mathrm{~cm}^{-1}$ to $[\mathrm{P}-\mathrm{O}]$ or $[\mathrm{P}-\mathrm{OH}]$ for $\mathrm{HPO}_{4}$ phosphate species of aqueous GP. Moreover, Persson et al. [57] assigned a band at $1178 \mathrm{~cm}^{-1}$ to [P-O] stretching mode for $\mathrm{FeH}_{2} \mathrm{PO}_{4}$ and Kubicki et al. [44] listed a band at $1176 \mathrm{~cm}^{-1}$ for the $\mathrm{FeHPO}_{4}$ phosphate species. The band at $1211 \mathrm{~cm}^{-1}$ could be assigned to stretching modes of [C-C-C] and [C-O-C] of glycerol group based on the assignment by Nakagawa and Oyama [92] of $1210 \mathrm{~cm}^{-1}$ frequency observed in glycerol-water interactions [93]. Regarding the next band at $1244 \mathrm{~cm}^{-1}$, Kubicki et al. [44] assigned the band at $1250 \mathrm{~cm}^{-1}$ to [P-O-H] bending vibrations and in addition, Ahmed et al. [15] assigned the band at $1227 \mathrm{~cm}^{-1}$ to $[\mathrm{P}-\mathrm{O}-\mathrm{H}]$ bending vibrations for OP on 010 goethite surface. Therefore, the band at $1244 \mathrm{~cm}^{-1}$ here could be assigned to GP's unprotonated phosphate oxygens interaction with water hydrogens.

GP B motif case: Ahmed et al. [15] study of OP on 010 goethite surface assigned bands at 957 and $964 \mathrm{~cm}^{-1}$ to [O-P-2OFe] and [2O-P-OFe] symmetric stretching modes and Persson et al. [57] assigned the band at $966 \mathrm{~cm}^{-1}$ to [P-O] stretching mode. Therefore, the band at $951 \mathrm{~cm}^{-1}$ could be assigned to $[\mathrm{P}-\mathrm{O}]$ or $[\mathrm{P}-\mathrm{OFe}]$ stretching modes. The band at $994 \mathrm{~cm}^{-1}$ frequency is close to $998 \mathrm{~cm}^{-1}$ frequency found in GP M motif case, and therefore it is assigned the same modes, $[\mathrm{P}-\mathrm{O}]$ or $[\mathrm{P}-\mathrm{OFe}]$ stretching modes, as the latter frequency. The bands at 1043, 1115, and $1148 \mathrm{~cm}^{-1}$ could be assigned to [P-O] stretching mode as per Li et al. [29] study while the band at $1088 \mathrm{~cm}^{-1}$ could be assigned to [P=O] [29] or [P-O] [83] stretching modes, see Table 1 . The band at $1170 \mathrm{~cm}^{-1}$ is assigned [P-O] mode which is the same mode assigned for the band at $1176 \mathrm{~cm}^{-1}$ in GP $\mathbf{M}$ motif case. The band at 1191 and $1213 \mathrm{~cm}^{-1}$ could be assigned to [C-C-C] and [C-O-C] stretching modes of glycerol group as assigned for $1211 \mathrm{~cm}^{-1}$ frequency observed in GP M motif case. The band at $1236 \mathrm{~cm}^{-1}$ is assigned the same mode as $1244 \mathrm{~cm}^{-1}$ in GP $\mathbf{M}$ motif case.

Comparing IR spectra of GP $\mathbf{M}$ and $\mathbf{B}$ motifs, we conclude that several common band assignments are observed between both cases. The bands between 951 and $998 \mathrm{~cm}^{-1}$ are assigned to [P-O] or [P-OFe] stretching modes, and the ones between 1029 and $1176 \mathrm{~cm}^{-1}$ are assigned to $[\mathrm{P}-\mathrm{O}]$ stretching mode except for $1088 \mathrm{~cm}^{-1}$ frequency which could be assigned to $[\mathrm{P}=\mathrm{O}]$ stretching mode as well. The bands between 1191 and $1213 \mathrm{~cm}^{-1}$ are assigned to $[\mathrm{C}-\mathrm{C}-\mathrm{C}]$ and $[\mathrm{C}-\mathrm{O}-\mathrm{C}]$ stretching modes of glycerol group, respectively, while the bands between 1236 and $1244 \mathrm{~cm}^{-1}$ are assigned to unprotonated phosphate oxygens interaction with water hydrogens. The comparison of spectra calculated here with spectra from the experimental study by Li et al. [29] is shown in Figure S2a. Moreover, spectral peaks characteristic to water are analyzed in light of peaks from literature, see Figure S8. 
Table 1. Experimental and theoretical IR frequencies from selected studies related to phosphates OP, GP, IHP, and others on goethite are listed below. The IR frequencies calculated here for GP and IHP on goethite are also presented here. The symbols $\dagger, \ddagger$, $\bullet, \circ, \mathbf{\Lambda}, \cdots$, and $\star$ denote [P-O], [P=O], [P-OFe], [P-OH], [P-O-C], [P-O $\cdots \mathrm{H}$ ], and [C-C-C] plus [C-O-C] modes, respectively. The symbols are assigned to frequencies only when specifically mentioned in reference experimental study. The frequency assigned to multiple modes is denoted as $\bullet / \circ$ represent $[\mathrm{P}-\mathrm{OFe}]$ or $[\mathrm{P}-\mathrm{OH}]$ modes while $\bullet \& / \circ$ represent $[\mathrm{P}-\mathrm{OFe}]$ and $/$ or $[\mathrm{P}-\mathrm{OH}]$ mode.

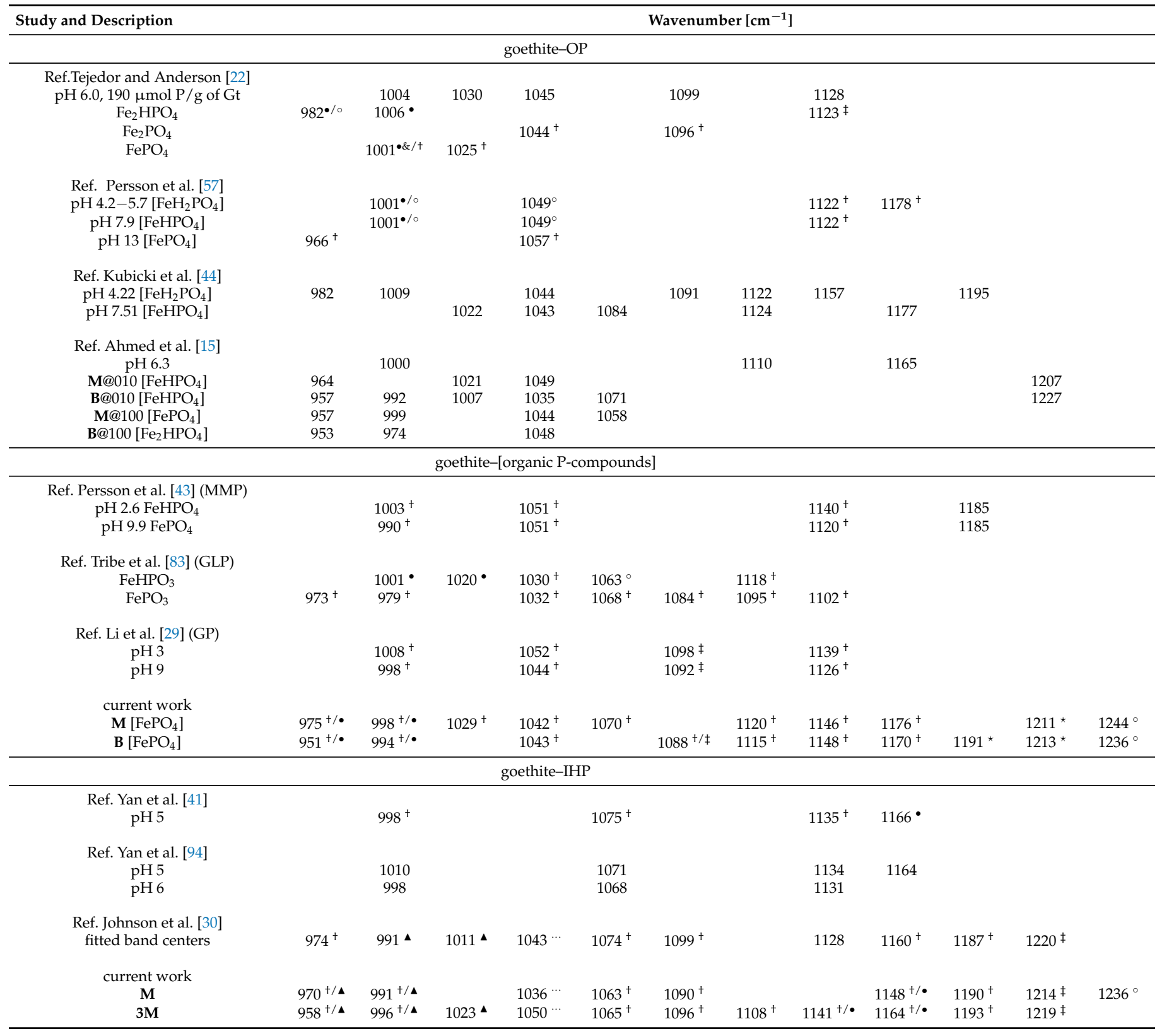

\subsubsection{IHP IR Spectra}

IHP has six phosphate groups and hence the theoretical spectra calculated here would include the characteristics of different types of phosphate species originating from the six phosphate groups. In addition, intermolecular HBs are also common between adjacent phosphate groups which shift or alter intensity of the IR spectra [88,89]. In the IHP M case, the six phosphate groups transformed to two types of phosphate species, $\mathrm{HPO}_{4}(2)$ and $\mathrm{H}_{2} \mathrm{PO}_{4}(4)$, in the production trajectory. The IR spectra for IHP $\mathbf{M}$ case exhibited bands at $970,991,1036,1063,1090,1148,1190,1214$, and $1236 \mathrm{~cm}^{-1}$, see Figure $5 \mathrm{~b}$. The first five bands are high intense bands while the latter ones are moderately intense to often less 
intense. The band at $1090 \mathrm{~cm}^{-1}$ is a shoulder band distributed in the frequency range of 1084 to $1099 \mathrm{~cm}^{-1}$ while the band at 1214 is a least intense flat band distributed in the frequency range of 1205 to $1222 \mathrm{~cm}^{-1}$. In IHP $3 \mathrm{M}$ motif case all possible phosphate species, $\mathrm{PO}_{4}(1), \mathrm{HPO}_{4}(2), \mathrm{H}_{2} \mathrm{PO}_{4}(3)$, are observed in the production trajectory. The IR spectra have bands at 958, 996, 1023, 1050, 1065, 1096, 1108, 1141, 1164, 1193, and $1219 \mathrm{~cm}^{-1}$. The bands at 1065 and $1219 \mathrm{~cm}^{-1}$ are shoulder bands distributed in the frequency range of 1059 to $1071 \mathrm{~cm}^{-1}$ and $1212-1225 \mathrm{~cm}^{-1}$, respectively. The bands at 1096 and $1108 \mathrm{~cm}^{-1}$ are maxima of a bimodal peak which is distributed in the frequency range of 1084 to $1116 \mathrm{~cm}^{-1}$. The IHP M and IHP 3M motif cases have matching bands within $\pm 6 \mathrm{~cm}^{-1}$ of frequencies at 964, 993, 1064, 1093, 1144, 1191, and $1217 \mathrm{~cm}^{-1}$. The IHP spectra obtained here are deconvoluted into Gaussian functions using the PeakFit v4 software [95] to compare current results with Johnson et al. [30] study. PeakFit v4 is the same software used by Johnson et al. [30] for deconvolution of IHP spectra. The deconvoluted spectra and the corresponding fitted band centers are presented in Figure S1.

IHP M case: Guan et al. [45] assigned bands between $970-985 \mathrm{~cm}^{-1}$ and $970 \mathrm{~cm}^{-1}$ frequency to $[\mathrm{P}-\mathrm{O}-\mathrm{C}]$ stretching mode for IHP adsorbed onto aluminum hydroxide and for IHP in water, respectively. In contrast, Johnson et al. [30] assigned a fitted band center at $974 \mathrm{~cm}^{-1}$ to [P-O] mode but he assigned fitted band center at 991 and $1011 \mathrm{~cm}^{-1}$ to $[\mathrm{P}-\mathrm{O}-\mathrm{C}]$ stretching mode. Therefore, the peaks at 970 and $991 \mathrm{~cm}^{-1}$ (fitted band centers at 967 and $992 \mathrm{~cm}^{-1}$, respectively, see Figure S1a) could be assigned to [P-O] or [P-O-C] stretching modes. The band at $1036 \mathrm{~cm}^{-1}$ (fitted band center $1036 \mathrm{~cm}^{-1}$ ) might correspond to the intermolecular HBs between adjacent phosphate groups or between a phosphate group and water adsorbed to goethite surface. This assignment is based on the study of Johnson et al. [30], where the fitted band center at $1043 \mathrm{~cm}^{-1}$ is assigned to $\mathrm{P}-\mathrm{O} \cdots \mathrm{H}(\mathrm{H}$ from the phosphate group or water adsorbed to goethite surface). The high intense peak at $1063 \mathrm{~cm}^{-1}$ with fitted band center at peak center could be assigned to [P-O] stretching mode of $\mathrm{HPO}_{4}$ as per Johnson et al. [30] and Yan et al. [41] studies, see Table 1. The next peak is at $1090 \mathrm{~cm}^{-1}$ (fitted band center at $1091 \mathrm{~cm}^{-1}$ ) and it could be assigned to [P-O] mode as Johnson et al. [30] assigned a fitted band at 1099 to such a mode. The fitted band center at $1120 \mathrm{~cm}^{-1}$ which does not have a specific assigned peak (see Figure S1a) might correspond to [P-O] stretching mode as Johnson et al. [30] assigned fitted band center at $1128 \mathrm{~cm}^{-1}$ to [P-O] stretching mode. The peak at $1148 \mathrm{~cm}^{-1}$ (fitted band centers at 1147 and $1165 \mathrm{~cm}^{-1}$ ) might correspond to [P-OFe] stretching mode as Guan et al. [45] and Yan et al. [41] assigned bands $1148 \mathrm{~cm}^{-1}, 1157 \mathrm{~cm}^{-1}$, and $1166 \mathrm{~cm}^{-1}$ to [P-OAl] and [P-OFe] stretching modes, respectively. It could also be assigned to [P-O] mode as Johnson et al. [30] assigned $1160 \mathrm{~cm}^{-1}$ band center to such a mode. The peak at $1190 \mathrm{~cm}^{-1}$ the fitted band center is at peak center and it is assigned to [P-O] mode as per Johnson et al. [30]. The band at $1214 \mathrm{~cm}^{-1}$ (fitted band center at $1213 \mathrm{~cm}^{-1}$ ) could be assigned to $[\mathrm{P}=\mathrm{O}]$ stretching mode. This is because, Celi et al. [31] suggested that after IHP adsorption onto goethite the $[\mathrm{P}=\mathrm{O}]$ stretching band observed for aqueous IHP at $1223 \mathrm{~cm}^{-1}$ frequency might shift to lower frequencies. In addition, Johnson et al. [30] assigned the fitted band center at $1220 \mathrm{~cm}^{-1}$ to $[\mathrm{P}=\mathrm{O}]$ stretching mode. Bands within 1230 and $1250 \mathrm{~cm}^{-1}$ are not common in goethiteIHP-related studies, see Table 1 , and therefore the band at $1239 \mathrm{~cm}^{-1}$ is assigned to [P-O-H] bending vibrations based on Ahmed et al. [15]'s study.

IHP 3M motif case: The first band at $958 \mathrm{~cm}^{-1}$ could be assigned to [P-O] or [P-O-C] stretching modes based on reasons for assignment of $970 \mathrm{~cm}^{-1}$ band in IHP M motif case. The next band at $996 \mathrm{~cm}^{-1}$ is assigned to $[\mathrm{P}-\mathrm{O}]$ or $[\mathrm{P}-\mathrm{O}-\mathrm{C}]$ stretching modes for the same reasons as given for the assignment of the $977 \mathrm{~cm}^{-1}$ band in IHP M motif case. The band at $1023 \mathrm{~cm}^{-1}$ (fitted band center at $1022 \mathrm{~cm}^{-1}$ ) could be assigned to [P-O-C] stretching mode, as Johnson et al. [30] assigned the fitted band center at $1011 \mathrm{~cm}^{-1}$ to such a mode. Similar to the band at $1036 \mathrm{~cm}^{-1}$ for IHP M motif case, the band at $1050 \mathrm{~cm}^{-1}$ (fitted band center at $1048 \mathrm{~cm}^{-1}$ ) here could be assigned to inter- and intramolecular HBs among adjacent phosphate groups and a phosphate group with water bound to goethite, respectively. The next bands at 1065 and $1096 \mathrm{~cm}^{-1}$ (corresponding fitted band centers at 
1068 and $1092 \mathrm{~cm}^{-1}$ ) are assigned to [P-O] stretching modes similar to peaks at 1063 and $1090 \mathrm{~cm}^{-1}$ of IHP M motif case, see Table 1 . The peak at $1108 \mathrm{~cm}^{-1}$ with fitted band center at $1113 \mathrm{~cm}^{-1}$ could be assigned to [P-O] stretching mode based on Johnson et al. [30] assignment of fitted band center at $1127 \mathrm{~cm}^{-1}$ to [P-O] stretching mode. The band at $1141 \mathrm{~cm}^{-1}$ (fitted band center at $1140 \mathrm{~cm}^{-1}$ ) is assigned to [P-OFe] stretching mode as Guan et al. [45] assigned the band at $1048 \mathrm{~cm}^{-1}$ to [P-OAl] stretching mode. It could also be assigned to [P-O] mode since Yan et al. [41] assigned the band at $1135 \mathrm{~cm}^{-1}$ to [P-O] mode. The band $1164 \mathrm{~cm}^{-1}$ (fitted band center at $1165 \mathrm{~cm}^{-1}$ ) is assigned to [P-OFe] or $[\mathrm{P}-\mathrm{O}]$ mode, as Yan et al. [41] assigned the band at $1166 \mathrm{~cm}^{-1}$ to $[\mathrm{P}-\mathrm{OFe}]$ stretching mode and Johnson et al. [30] assigned fixed band center at 1162 to [P-O] mode. The peaks at 1193 and $1219 \mathrm{~cm}^{-1}$ are assigned to $[\mathrm{P}-\mathrm{O}]$ and $[\mathrm{P}=\mathrm{O}]$ modes for the same reasons given the assignment of peaks at 1190 and $1214 \mathrm{~cm}^{-1}$ in IHP M motif case.

Summarizing the IHP M and 3M motifs' IR spectra, and their assignments based on literature (see Table 1), we conclude the following. The bands in the frequency range of 958 to $996 \mathrm{~cm}^{-1}$ could be mainly assigned to [P-O] or [P-O-C] stretching modes. The bands around $1043 \mathrm{~cm}^{-1}$ are assigned to intermolecular HBs between IHPs phosphate groups and intramolecular HBs between IHP phosphate groups and water adsorbed to goethite. The bands observed in the range of 1063 to $1108 \mathrm{~cm}^{-1}$ are assigned to [P-O] stretching modes and the ones in 1141-1164 $\mathrm{cm}^{-1}$ frequency range are assigned to [P-OFe] or [P-O] modes. The peaks around $1191 \mathrm{~cm}^{-1}$ are assigned to $[\mathrm{P}-\mathrm{O}]$ modes and the ones around $1217 \mathrm{~cm}^{-1}$ are assigned to $[\mathrm{P}=\mathrm{O}]$ modes. The comparison of IHP spectra with spectra from the experimental study of Yan et al. [41] is shown in Figure S2b. A few selected frequency ranges where the IR spectra of water could be characterized are analyzed, see Figure S8.

\section{Summary and Conclusions}

The world population is expected to increase 34\% by 2050 and will reach 9.1 billion [96], challenging the agricultural industry to meet the nutritional needs. Unfortunately, agricultural production is heavily dependent on the soon to be exhausted P rocks. Therefore, there is a need to find ways to recycle and secure P resources to support the raising global population. The current study focused on P interaction with soil minerals, a significant factor that causes $\mathrm{P}$ inefficiency and $\mathrm{P}$ loss in soil. The present results are expected to provide additional insight into organic $P$ interaction at goethite-water interface.

Analysis of binding energies (see Figure 2) show that the GP B motif exhibits stronger overall binding energy than the $\mathbf{M}$ motif. This is in contrast to the suggestion by Li et al. [29] that GP might not form B motif due to steric hinderance of organic moiety. However, based on interaction energies calculated here and the study by Abdala et al. [58], we conclude that GP forms a B motif at low goethite surface loading, while at high loading the $\mathbf{M}$ motif dominates.

Regarding IHP, it is found to interact with goethite through multiple phosphate groups and its 3M motif has a higher interaction energy than the $\mathbf{M}$ motif. Furthermore, its $\mathbf{B}$ motif is unstable which transformed to the $\mathbf{M}$ motif. The transformation of the $\mathbf{B}$ to the $\mathbf{M}$ motif has occurred in our previous studies $[47,48]$ as well, confirming that IHP phosphate groups are more likely to form $\mathbf{M}$ motifs with goethite. The IHP interaction energy with goethite is stronger than for GP which suggests that it could replace GP to bind with goethite. This is in line with the results of De Groot and Golterman [97] which showed that IHP can replace $\mathrm{OP}$ and inhibit it from further adsorption.

The energy required for phosphate to replace a $\mathrm{OH}^{-}$from the surface could not be estimated from that study. However, Ahmed et al. [15] showed that $\mathrm{OH}^{-}$has a higher interaction energy than OP and water and thus could replace both. However, in contrast, Li et al. [29] showed that GP replaces $\mathrm{OH}^{-}$at the goethite surface at a high rate. Therefore, understanding the priority of adsorption is important as a non-replaceable hydroxyl group at the surface could restrict the IHP interaction with goethite and also reduce the range of binding motifs. The current study proposes a competitive adsorption study for multiple 
instances of IHP/GP in presence of water and $\mathrm{OH}^{-}$at the goethite surface to understand effect of high surface loading and influence of $\mathrm{OH}^{-}$on binding motifs.

Finally, we have investigated the IR signatures of the different binding motifs. The IR spectra calculated for GP $\mathbf{M}$ and $\mathbf{B}$ motifs match reasonably with phosphates related IR spectra from literature. This suggests that both motifs might exist simultaneously on the goethite surface. However, given the similarity of spectra, the proportion of these motifs could not be estimated as done by Ahmed et al. [15]. The calculated IR spectra for IHP also matches well with the IR spectra from literature. This validates the current modeling approach for simulating the interactions of IHP and GP at goethite-water interface.

Supplementary Materials: The following are available online, Figure S1: Fitted IR spectra of IHP, Figure S2: Comparison of GP and IHP spectra with experimental spectra, Figure S3: Initial motifs of IHP and GP, Figure S4: GP BB motif, HBs between GP and surrounding water and water bonded to surface Fe atoms, Figure S5: Pair correlation function for surface Fe atoms and water oxygens, Figure S6: Fe- $\mathrm{O}_{\mathrm{p}}$ covalent bond lengths along simulation trajectories between 25 and 55 ps, Figure S7: Binding energy of IHP M(1) motif along simulation trajectory between 25 and 55 ps, Figure S8: IR spectra of GP M and B motif cases and IHP M and 3M motif cases.

Author Contributions: P.B.G. is responsible for formal analysis, investigation, methodology, visualization and writing-original draft. A.A.A. and O.K. are responsible for conceptualization, funding acquisition, methodology, supervision, writing-review and editing. All authors have read and agreed to the published version of the manuscript.

Funding: We gratefully acknowledge the financial support by the German Research Foundation (DFG) as a part of the SPP 1685 Priority program “Ecosystem Nutrition: Forest strategies for limited phosphorus resources" (P.B.G., O.K., A.A.A.) and the InnoSoilPhos-project (A.A.A.), funded by the German Federal Ministry of Education and Research (BMBF) in the frame of the BonaRes-program (No. 031A558). This research was performed within the scope of the Leibniz Science Campus "Phosphorus Research Rostock". The authors thank the North German Super computing Alliance for providing HPC resources (project mvp00016).

Data Availability Statement: Not applicable.

Conflicts of Interest: The authors declare no conflict of interest. The funders had no role in the design of the study; in the collection, analyses, or interpretation of data; in the writing of the manuscript; or in the decision to publish the results.

\section{References}

1. Cordell, D.; Drangert, J.O.; White, S. The Story of Phosphorus: Global Food Security and Food for Thought. Glob. Environ. Chang. 2009, 19, 292-305. [CrossRef]

2. Cordell, D.; Neset, T.S.S. Phosphorus Vulnerability: A Qualitative Framework for Assessing the Vulnerability of National and Regional Food Systems to the Multi-Dimensional Stressors of Phosphorus Scarcity. Glob. Environ. Chang. 2014, $24,108-122$. [CrossRef]

3. Reitzel, K.; Bennett, W.W.; Berger, N.; Brownlie, W.J.; Bruun, S.; Christensen, M.L.; Cordell, D.; van Dijk, K.; Egemose, S.; Eigner, H.; et al. New Training to Meet the Global Phosphorus Challenge. Environ. Sci. Technol. 2019, 53, 8479-8481. [CrossRef]

4. Steen, I. Phosphorus Availability in the 21st Century : Management of a Non-Renewable Resource. Phosphorus Potassium 1998, 217, 25-31.

5. Smil, V. Phosphorus in the Environment: Natural Flows and Human Interferences. Annu. Rev. Environ. Resour. 2000, 25, 53-88. [CrossRef]

6. Rosmarin, A. The Precarious Geopolitics of Phosphorous. Down Earth Sci. Environ. Fortn. 2004, 30, $27-31$.

7. Withers, P. Closing the Phosphorus Cycle. Nat. Sustain. 2019, 1001-1002. [CrossRef]

8. Withers, P.; Forber, K.; Lyon, C.; Rothwell, S.; Doody, D.; Jarvie, H.; Martin-Ortega, J.; Jacobs, B.; Cordell, D.; Patton, M.; et al. Towards Resolving the Phosphorus Chaos Created by Food Systems. Ambio A J. Hum. Environ. 2019. [CrossRef]

9. Ahmed, A.A.; Gros, P.; Kühn, O.; Leinweber, P. Molecular Level Investigation of the Role of Peptide Interactions in the Glyphosate Analytics. Chemosphere 2018, 196, 129-134. [CrossRef]

10. Gros, P.; Ahmed, A.; Kühn, O.; Leinweber, P. Glyphosate Binding in Soil as Revealed by Sorption Experiments and QuantumChemical Modeling. Sci. Total Environ. 2017, 586, 527-535. [CrossRef]

11. Gros, P.; Ahmed, A.A.; Kühn, O.; Leinweber, P. Influence of Metal Ions on Glyphosate Detection by FMOC-Cl. Environ. Model. Assess. 2019, 191, 244. [CrossRef] [PubMed] 
12. Hens, M.; Merckx, R. Functional Characterization of Colloidal Phosphorus Species in the Soil Solution of Sandy Soils. Environ. Sci. Technol. 2001, 35, 493-500. [CrossRef] [PubMed]

13. Kruse, J.; Abraham, M.; Amelung, W.; Baum, C.; Bol, R.; Kühn, O.; Lewandowski, H.; Niederberger, J.; Oelmann, Y.; Rüger, C.; et al. Innovative Methods in Soil Phosphorus Research: A Review. J. Soil Sci. Plant Nutr. 2015, 178, 43-88. [CrossRef] [PubMed]

14. Jiang, X.; Bol, R.; Nischwitz, V.; Siebers, N.; Willbold, S.; Vereecken, H.; Amelung, W.; Klumpp, E. Phosphorus Containing Water Dispersible Nanoparticles in Arable Soil. J. Environ. Qual. 2015, 44, 1772-1781. [CrossRef] [PubMed]

15. Ahmed, A.A.; Gypser, S.; Leinweber, P.; Freese, D.; Kühn, O. Infrared Spectroscopic Characterization of Phosphate Binding at the Goethite-Water Interface. Phys. Chem. Chem. Phys. 2019, 21, 4421-4434. [CrossRef] [PubMed]

16. Gypser, S.; Hirsch, F.; Schleicher, A.M.; Freese, D. Impact of Crystalline and Amorphous Iron- and Aluminum Hydroxides on Mechanisms of Phosphate Adsorption and Desorption. J. Environ. Sci. 2018, 70, 175-189. [CrossRef]

17. Sharpley, A.N.; Chapra, S.C.; Wedepohl, R.; Sims, J.T.; Daniel, T.C.; Reddy, K.R. Managing Agricultural Phosphorus for Protection of Surface Waters: Issues and Options. J. Environ. Qual. 1994, 23, 437-451. [CrossRef]

18. Holzmann, S.; Missong, A.; Puhlmann, H.; Siemens, J.; Bol, R.; Klumpp, E.; von Wilpert, K. Impact of Anthropogenic Induced Nitrogen Input and Liming on Phosphorus Leaching in Forest Soils. J. Soil Sci. Plant Nutr. 2015, 179, 443-453. [CrossRef]

19. Bol, R.; Julich, D.; Brödlin, D.; Siemens, J.; Kaiser, K.; Dippold, M.A.; Spielvogel, S.; Zilla, T.; Mewes, D.; von Blanckenburg, F.; et al. Dissolved and Colloidal Phosphorus Fluxes in Forest Ecosystems-An Almost Blind Spot in Ecosystem Research. J. Soil Sci. Plant Nutr. 2016, 179, 425-438. [CrossRef]

20. Boy, J.; Valarezo, C.; Wilcke, W. Water Flow Paths in Soil Control Element Exports in an Andean Tropical Montane Forest. Eur. J. Soil Sci. 2008, 59, 1209-1227. [CrossRef]

21. Newman, R.H.; Tate, K.R. Soil Phosphorus Characterisation by 31 P Nuclear Magnetic Resonance. Commun. Soil Sci. Plant Anal. 1980, 11, 835-842. [CrossRef]

22. Tejedor-Tejedor, M.I.; Anderson, M.A. The Protonation of Phosphate on the Surface of Goethite as Studied by CIR-FTIR and Electrophoretic Mobility. Langmuir 1990, 6, 602-611. [CrossRef]

23. Turner, B.L.; Papházy, M.J.; Haygarth, P.M.; Mckelvie, I.D. Inositol Phosphates in the Environment. Philos. Trans. R. Soc. B 2002, 357, 449-469. [CrossRef] [PubMed]

24. Doolette, A.; Smernik, R.; Dougherty, W. Spiking Improved Solution Phosphorus31 Nuclear Magnetic Resonance Identification of Soil Phosphorus Compounds. Soil Sci. Soc. Am. J. 2009, 73. [CrossRef]

25. Gerke, J. Phytate (Inositol Hexakisphosphate) in Soil and Phosphate Acquisition from Inositol Phosphates by Higher Plants: A Review. Plants 2015, 4, 253-266. [CrossRef]

26. Pant, H.K.; Warman, P.R.; Nowak, J. Identification of Soil Organic Phosphorus by 31 P Nuclear Magnetic Resonance Spectroscopy. Commun. Soil. Sci. Plant Anal. 1999, 30, 757-772. [CrossRef]

27. Vincent, A.G.; Vestergren, J.; Gröbner, G.; Persson, P.; Schleucher, J.; Giesler, R. Soil Organic Phosphorus Transformations in a Boreal Forest Chronosequence. Plant Soil 2013, 367, 149-162. [CrossRef]

28. Missong, A.; Bol, R.; Willbold, S.; Siemens, J.; Klumpp, E. Phosphorous Forms in Forest Soil Colloids as Revealed by Liquid-State P-NMR. J. Soil Sci. Plant Nutr. 2016, 179, 159-167. [CrossRef]

29. Li, H.; Wan, B.; Yan, Y.; Zhang, Y.; Cheng, W.; Feng, X. Adsorption of Glycerophosphate on Goethite: A Macroscopic and Infrared Spectroscopic Study. J. Soil Sci. Plant Nutr. 2017, 181, 557-565. [CrossRef]

30. Johnson, B.B.; Quill, E.; Angove, M.J. An Investigation of the Mode of Sorption of Inositol Hexaphosphate to Goethite. J. Colloid Interface Sci. 2012, 367, 436-442. [CrossRef]

31. Celi, L.; M, P.; Marsan, F.A.; Barberis, E. Effects of $\mathrm{pH}$ and Electrolytes on Inositol Hexaphosphate Interaction with Goethite. Soil Sci. Soc. Am. J. 2001, 65, 753-760. [CrossRef]

32. Tsao, T.M.; Chen, Y.M.; Wang, M.K. Origin, Separation and Identification of Environmental Nanoparticles: A Review. J. Environ. Monit. 2011, 13, 1156-1163. [CrossRef]

33. Tan, K. Principles of Soil Chemistry, 4th ed.; Books in Soils, Plants, and the Environment; Taylor \& Francis: Abingdon, UK, 2011.

34. Brady, N. The Nature and Properties of Soils, 15th ed.; Pearson Education Ltd.: Pearson, Harlow, UK, 2017.

35. Cornell, R.M.; Schwertmann, U. The Iron Oxides: Structure, Properties Reactions Occurrence and Uses; Wiley-VCH Verlag GmbH and Co. KGaA: Weinheim, Germany, 2003. [CrossRef]

36. Parfitt, R.L.; Atkinson, R.J. Phosphate Adsorption on Goethite ( $\alpha$-FeOOOH). Nature 1976, 264, 740-742. [CrossRef]

37. Torrent, J.; Schwertmann, U.; Barron, V. Fast and Slow Phosphate Sorption by Goethite-Rich Natural Materials. Clays Clay Miner. 1992, 40, 14-21. [CrossRef]

38. Chitrakar, R.; Tezuka, S.; Sonoda, A.; Sakane, K.; Ooi, K.; Hirotsu, T. Phosphate Adsorption on Synthetic Goethite and Akaganeite. J. Colloid Interface Sci. 2006, 298, 602-608. [CrossRef]

39. Ahmed, A.A.; Gypser, S.; Freese, D.; Leinweber, P.; Kuehn, O. Molecular Level Picture of the Interplay between pH and Phosphate Binding at the Goethite-Water Interface. Phys. Chem. Chem. Phys. 2020. [CrossRef] [PubMed]

40. Ognalaga, M.; Frossard, E.; Thomas, F. Glucose-1-Phosphate and Myo-Inositol Hexaphosphate Adsorption Mechanisms on Goethite. Soil Sci. Soc. Am. J. 1994, 332-337. [CrossRef]

41. Yan, Y.; Koopal, L.K.; Liu, F.; Huang, Q.; Feng, X. Desorption of Myo-Inositol Hexakisphosphate and Phosphate from Goethite by Different Reagents. J. Plant. Nutr. Soil Sci. 2015, 178, 878-887. [CrossRef]

42. Kubicki, J.D. (Ed.) Molecular Modeling of Geochemical Reactions; Wiley and Sons: Chichester, UK, 2016. 
43. Persson, P.; Andersson, T.; Nelson, H.; Sjöberg, S.; Giesler, R.; Lövgren, L. Surface Complexes of Monomethyl Phosphate Stabilized by Hydrogen Bonding on Goethite (Alpha-FeOOH) Nanoparticles. J. Colloid Interface Sci. 2012, 386, 350-358. [CrossRef]

44. Kubicki, J.D.; Paul, K.W.; Kabalan, L.; Zhu, Q.; Mrozik, M.K.; Aryanpour, M.; Pierre-Louis, A.M.; Strongin, D.R. ATR-FTIR and Density Functional Theory Study of the Structures, Energetics, and Vibrational Spectra of Phosphate Adsorbed onto Goethite. Langmuir 2012, 28, 14573-14587. [CrossRef]

45. Guan, X.H.; Shang, C.; Zhu, J.; Chen, G.H. ATR-FTIR Investigation on the Complexation of Myo-Inositol Hexaphosphate with Aluminum Hydroxide. J. Colloid Interface Sci. 2006, 293, 296-302. [CrossRef] [PubMed]

46. Ahmed, A.A.; Leinweber, P.; Kühn, O. Unravelling the Nature of Glyphosate Binding to Goethite Surfaces by Ab Initio Molecular Dynamics Simulations. Phys. Chem. Chem. Phys. 2018, 20, 1531-1539. [CrossRef] [PubMed]

47. Ganta, P.B.; Kühn, O.; Ahmed, A.A. QM/MM Simulations of Organic Phosphorus Adsorption at the Diaspore-Water Interface. Phys. Chem. Chem. Phys. 2019, 21, 24316-24325. [CrossRef] [PubMed]

48. Ganta, P.B.; Kühn, O.; Ahmed, A.A. QM/MM Molecular Dynamics Investigation of the Binding of Organic Phosphates to the 100 Diaspore Surface. Front. For. Glob. Chang. 2020, 3, 71. [CrossRef]

49. Gerzabek, M.; Aquino, A.; Haberhauer, G.; Tunega, D.; Lischka, H. Molecular Modelling-Opportunities for Soil Research. Bodenkultur 2001, 52, 133-146.

50. Kwon, K.D.; Kubicki, J.D. Molecular Orbital Theory Study on Surface Complex Structures of Phosphates to Iron Hydroxides: Calculation of Vibrational Frequencies and Adsorption Energies. Langmuir 2004, 20, 9249-9254. [CrossRef]

51. Aquino, A.J.; Tunega, D.; Haberhauer, G.; Gerzabek, M.H.; Lischka, H. Acid-Base Properties of a Goethite Surface Model: A Theoretical View. Geochim. Cosmochim. Acta 2008, 72, 3587-3602. [CrossRef]

52. Strauss, R.; BrÜmmer, G.; BARROW, N. Effects of Crystallinity of Goethite: II. Rates of Sorption and Desorption of Phosphate. Eur. J. Soil Sci. 1997, 48, 101-114. [CrossRef]

53. Kosmulski, M. pH-Dependent Surface Charging and Points of Zero Charge. IV. Update and New Approach. J. Colloid Interface Sci. 2009, 337, 439-448. [CrossRef]

54. Senn, H.M.; Thiel, W. QM/MM Methods for Biomolecular Systems. Angew. Chem. 2009, 48, 1198-1229. [CrossRef]

55. Xiu, F.; Zhou, L.; Xia, S.; Yu, L. Adsorption Mechanism of Water Molecule on Goethite (010) Surface. J. Ocean Univ. China 2016, 15, 1021-1026. [CrossRef]

56. Guo, H.; Barnard, A.S. Thermodynamic Modelling of Nanomorphologies of Hematite and Goethite. J. Mater. Chem. 2011, 21, 11566-11577. [CrossRef]

57. Persson, P.; Nilsson, N.; Sjöberg, S. Structure and Bonding of Orthophosphate Ions at the Iron Oxide-Aqueous Interface. J. Colloid Interface Sci. 1996, 177, 263-275. [CrossRef]

58. Abdala, D.B.; Northrup, P.A.; Arai, Y.; Sparks, D.L. Surface Loading Effects on Orthophosphate Surface Complexation at the Goethite/Water Interface as Examined by Extended X-Ray Absorption Fine Structure (EXAFS) Spectroscopy. J. Colloid Interface Sci. 2015, 437, 297-303. [CrossRef]

59. Humphrey, W.; Dalke, A.; Schulten, K. VMD—Visual Molecular Dynamics. J. Mol. Graph. 1996, 14, 33-38. [CrossRef]

60. Groenhof, G. Introduction to QM/MM Simulations. In Biomolecular Simulations: Methods and Protocols; Monticelli, L., Salonen, E., Eds.; Humana Press: Totowa, NJ, USA, 2013; pp. 43-66. [CrossRef]

61. Ozboyaci, M.; Kokh, D.B.; Corni, S.; Wade, R.C. Modeling and Simulation of Protein-Surface Interactions: Achievements and Challenges. Q. Rev. Biophys. 2016, 49, e4. [CrossRef]

62. VandeVondele, J.; Krack, M.; Mohamed, F.; Parrinello, M.; Chassaing, T.; Hutter, J. Quickstep: Fast and Accurate Density Functional Calculations Using a Mixed Gaussian and Plane Waves Approach. Comput. Phys. Commun. 2005, 167, 103-128. [CrossRef]

63. Krack, M. Pseudopotentials for $\mathrm{H}$ to Kr Optimized for Gradient-Corrected Exchange-Correlation Functionals. Theor. Chem. Acc. 2005, 114, 145-152. [CrossRef]

64. VandeVondele, J.; Hutter, J. Gaussian Basis Sets for Accurate Calculations on Molecular Systems in Gas and Condensed Phases. J. Chem. Phys. 2007, 127. [CrossRef]

65. Perdew, J.P.; Burke, K.; Ernzerhof, M. Generalized Gradient Approximation Made Simple. Phys. Rev. Lett. 1996, 77, 3865-3868. [CrossRef]

66. Grimme, S.; Antony, J.; Ehrlich, S.; Krieg, H. A Consistent and Accurate Ab Initio Parametrization of Density Functional Dispersion Correction (DFT-D) for the 94 Elements H-Pu. J. Phys. Chem. 2010, 132. [CrossRef] [PubMed]

67. Mundy, C.J.; Balasubramanian, S.; Bagchi, K.; Hutter, J.; Kuo, A.S.I.; Laino, T.; VandeVondele, J. Frontiers in Simulation Technology (FIST). (accessed by CP2K, version 5.1). 2017. Available online: www.cp2k.org (accessed on 12 November 2020).

68. CP2K. Open Source Molecular Dynamics Code. version 5.1, Released October 24, 2017 (r18096). Available online: https: / / www.cp2k.org/ (accessed on 12 November 2020).

69. Kühne, T.D.; Iannuzzi, M.; Del Ben, M.; Rybkin, V.V.; Seewald, P.; Stein, F.; Laino, T.; Khaliullin, R.Z.; Schütt, O.; Schiffmann, F.; et al. CP2K: An electronic structure and molecular dynamics software package-Quickstep: Efficient and accurate electronic structure calculations. J. Chem. Phys. 2020, 152, 194103. [CrossRef]

70. Cygan, R.T.; Liang, J.J.; Kalinichev, A.G. Molecular Models of Hydroxide, Oxyhydroxide, and Clay Phases and the Development of a General Force Field. J. Phys. Chem. B 2004, 108, 1255-1266. [CrossRef] 
71. Berendsen, H.J.C.; Grigera, J.R.; Straatsma, T.P. The Missing Term in Effective Pair Potentials. J. Phys. Chem. 1987, 91, 6269-6271. [CrossRef]

72. Zoete, V.; Cuendet, M.A.; Grosdidier, A.; Michielin, O. SwissParam: A Fast Force Field Generation Tool for Small Organic Molecules. J. Comput. Chem. 2011, 32, 2359-2368. [CrossRef] [PubMed]

73. Laino, T.; Mohamed, F.; Laio, A.; Parrinello, M. An Efficient Linear-Scaling Electrostatic Coupling for Treating Periodic Boundary Conditions in QM/MM Simulations. J. Chem. Theory Comput. 2006, 2, 1370-1378. [CrossRef] [PubMed]

74. Bussi, G.; Donadio, D.; Parrinello, M. Canonical Sampling through Velocity Rescaling. J. Chem. Phys. 2007. [CrossRef]

75. Boys, S.F.; Bernardi, F. The Calculation of Small Molecular Interactions by the Differences of Separate Total Energies: Some Procedures with Reduced Errors. Mol. Phys. 1970, 19, 553-566. [CrossRef]

76. Brehm, M.; Kirchner, B. TRAVIS-A Free Analyzer and Visualizer for Monte Carlo and Molecular Dynamics Trajectories. J. Chem. Inf. Model. 2011, 51, 2007-2023. [CrossRef]

77. Thomas, M.; Brehm, M.; Fligg, R.; Vöhringer, P.; Kirchner, B. Computing Vibrational Spectra from Ab Initio Molecular Dynamics. Phys. Chem. Chem. Phys. 2013, 15, 6608-6622. [CrossRef]

78. Thomas, M.; Brehm, M.; Kirchner, B. Voronoi Dipole Moments for the Simulation of Bulk Phase Vibrational Spectra. Phys. Chem. Chem. Phys. 2015, 17, 3207-3213. [CrossRef] [PubMed]

79. Brehm, M.; Thomas, M. An Efficient Lossless Compression Algorithm for Trajectories of Atom Positions and Volumetric Data. J. Chem. Inf. Model. 2018, 58, 2092-2107. [CrossRef] [PubMed]

80. Lü, C.; Yan, D.; He, J.; Zhou, B.; Li, L.; Zheng, Q. Environmental Geochemistry Significance of Organic Phosphorus: An Insight from Its Adsorption on Iron Oxides. J. Appl. Geochem. 2017, 84, 52-60. [CrossRef]

81. Sheals, J.; Sjoberg, S.; Persson, P. Adsorption of Glyphosate on Goethite: Molecular Characterization of Surface Complexes. Environ. Sci. Technol. 2002, 36, 3090-3095. [CrossRef]

82. Rose, J.; Flank, A.M.; Masion, A.; Bottero, J.Y.; Elmerich, P. Nucleation and Growth Mechanisms of Fe Oxyhydroxide in the Presence of PO4 Ions. 2. P K-Edge EXAFS Study. Langmuir 1997, 13, 1827-1834. [CrossRef]

83. Tribe, L.; Kwon, K.D.; Trout, C.C.; Kubicki, J.D. Molecular Orbital Theory Study on Surface Complex Structures of Glyphosate on Goethite: Calculation of Vibrational Frequencies. Environ. Sci. Technol. 2006, 40, 3836-3841. [CrossRef]

84. Anderson, G.; Arlidge, E.Z. The Adsorption of Inositol Phosphates and Glycerophosphate by Soil Clays, Clay Minerals, and Hydrated Sesquioxides in Acid Media. J. Soil Sci. 1962, 13, 216-224. [CrossRef]

85. Celi, L.; Lamacchia, S.; Marsan, F.A.; Barberis, E. Interaction of Inositol Hexaphosphate on Clays: Adsorption and Charging Phenomena. Soil Sci. 1999, 164, 574-585. [CrossRef]

86. Colthup, N.B.; Daly, L.H.; Wiberley, S.E. Compounds Containing Boron, Silicon, Phosphorus, Sulfur, or Halogen. In Introduction to Infrared and Raman Spectroscopy, 3rd ed.; Colthup, N.B., Daly, L.H., Wiberley, S.E., Eds.; Academic Press: San Diego, CA, USA, 1990; Chapter 12, pp. 355-385. [CrossRef]

87. Olsson, R.; Giesler, R.; Loring, J.S.; Persson, P. Adsorption, Desorption, and Surface-Promoted Hydrolysis of Glucose-1-Phosphate in Aqueous Goethite (Alpha-Feooh) Suspensions. Langmuir 2010, 26, 18760-18770. [CrossRef]

88. Del Bene, J.E.; Jordan, M.J.T. Vibrational Spectroscopy of the Hydrogen Bond: An Ab Initio Quantum-Chemical Perspective. Null 1999, 18, 119-162. [CrossRef]

89. Fornaro, T.; Burini, D.; Biczysko, M.; Barone, V. Hydrogen-Bonding Effects on Infrared Spectra from Anharmonic Computations: Uracil-Water Complexes and Uracil Dimers. J. Phys. Chem. A 2015, 119, 4224-4236. [CrossRef]

90. Arai, Y.; Sparks, D. ATR-FTIR Spectroscopic Investigation on Phosphate Adsorption Mechanisms at the Ferrihydrite-Water Interface. J. Colloid Interface Sci. 2001, 241, 317-326. [CrossRef]

91. Lincoln, S.; Stranks, D. Phosphato Complexes of Cobalt(III). I. General Structural and Hydrolytic Properties. Aust. J. Chem. 1968, 21,37-56. [CrossRef]

92. Nakagawa, H.; Oyama, T. Molecular Basis of Water Activity in Glycerol-Water Mixtures. Front. Chem. 2019, 7, 731. [CrossRef]

93. Kataoka, Y.; Kitadai, N.; Hisatomi, O.; Nakashima, S. Nature of Hydrogen Bonding of Water Molecules in Aqueous Solutions of Glycerol by Attenuated Total Reflection (ATR) Infrared Spectroscopy. Appl. Spectrosc. 2011, 65, 436-441. [CrossRef] [PubMed]

94. Yan, Y.; Wan, B.; Zhang, Y.; Zhang, L.; Liu, F.; Feng, X. In Situ ATR-FTIR Spectroscopic Study of the Co-Adsorption of Myo-Inositol Hexakisphosphate and Zn(II) on Goethite. Soil Res. 2018, 56, 526-534. [CrossRef]

95. Peak Fit v4. Peak Separation and Analysis Software; SPSS Science, Inc.: Chicago, IL, USA, 2003.

96. FAO. FAO's Director-General on How to Feed the World in 2050. Popul. Dev. Rev. 2009, 35, 837-839. [CrossRef]

97. De Groot, C.J.; Golterman, H.L. On the Presence of Organic Phosphate in Some Camargue Sediments: Evidence for the Importance of Phytate. Hydrobiologia 1993, 252, 117-126. [CrossRef] 